\title{
miR-589-3p sponged by the IncRNA TINCR inhibits the proliferation, migration and invasion and promotes the apoptosis of breast cancer cells by suppressing the Akt pathway via IGF1R
}

\author{
FANGDONG GUO $^{1}$, XIAOYU ZHU $^{1}$, QINGQUAN ZHAO ${ }^{2}$ and QIRONG HUANG $^{3}$ \\ ${ }^{1}$ Department of Breast and Thyroid Surgery, Affiliated Zhongshan Hospital of Dalian University, Dalian, Liaoning 116001; \\ ${ }^{2}$ Department of Breast and Thyroid Surgery, The 2nd Affiliated Hospital of Fujian Medical University, Quanzhou, \\ Fujian 362000; ${ }^{3}$ Department of Breast and Thyroid Surgery, Chengdu Dongli Hospital, Chengdu, Sichuan 610000, P.R. China
}

Received November 26, 2019; Accepted March 17, 2020

DOI: $10.3892 /$ ijmm.2020.4666

\begin{abstract}
The long non-coding (lnc)RNA named tissue differentiation inducing non-protein coding RNA (TINCR) is a tumor marker that has not been studied in breast cancer. The present study aimed to investigate the TINCR-targeting micro (mi)RNAs and the regulatory mechanisms of TINCR in breast cancer. Following prediction by TargetScan and confirmation by dual-luciferase reporter assay, TINCR was demonstrated to be a target gene for miR-589-3p. The expression of TINCR and $\mathrm{miR}-589-3 \mathrm{p}$ in breast cancer and adjacent tissues was detected by reverse transcription-quantitative (RT-q)PCR, and the correlation between TINCR and miR-589-3p expression was determined by using Spearman correlation analysis. The 5-years survival was analyzed in patients with breast cancer according to TINCR expression (high or low). The effects of TINCR and miR-589-3p on the proliferation, apoptosis, migratory and invasive abilities of some breast cancer cell lines were detected by MTT assay, flow cytometry, wound healing assay and Transwell assay. The target gene of miR-589-3p was predicted and verified by TargetScan and dual-luciferase reporter assay, and the mechanism of miR-589-3p involvement in breast cancer cells was explored by overexpression or
\end{abstract}

Correspondence to: Dr Fangdong Guo, Department of Breast and Thyroid Surgery, Affiliated Zhongshan Hospital of Dalian University, 6 Jiefang Street, Dalian, Liaoning 116001, P.R. China E-mail: fangdo_guofd@163.com

Abbrevations: GEO, Gene Expression Omnibus; lncRNA, long non-coding RNA; miRNA, microRNA; STAU1, staufen1; TCGA, The Cancer Genome Atlas; TINCR, tissue differentiation inducing non-protein coding RNA

Key words: breast cancer, tissue differentiation inducing non-protein coding RNA, miR-589-3p, insulin-like growth factor 1 receptor/AKT downregulation of miR-589-3p in breast cancer cells. RT-qPCR and western blotting were used to determine the expression of the insulin-like growth factor 1 receptor (IGF1R)/AKT pathway-related genes. The results demonstrated that TINCR expression level was negatively correlated with miR-589-3p expression level in breast cancer tissues and that patients with high expression of TINCR presented with lower survival rates. In addition, TINCR overexpression in cancer cells inhibited miR-589-3p expression, and cell transfection with miR-589-3p mimic partially reversed the effect of TINCR overexpression on the promotion of cancer cell proliferation, migration and invasion, and on the inhibition of cancer cell apoptosis. Furthermore, IGF1R, which is a target gene of miR-589-3p, increased cancer cell proliferation, migration and invasion and inhibited cancer cell apoptosis; however, these effects were partially reversed by miR-589-3p mimic. Furthermore, the results demonstrated that miR-589-3p mimic could downregulate the protein expression of IGF1R and p-AKT. In addition, TINCR overexpression downregulated miR-589-3p expression level. miR-589-3p partially reversed the effects of TINCR overexpression on cancer cell proliferation, migration and invasion, and inhibited cancer cell apoptosis by inhibiting the IGF1R-Akt pathway. The results from the present study demonstrated that TINCR may sponge miR-589-3p in order to inhibit IGF1R-Akt pathway activation in breast cancer cells, promoting therefore cancer cell proliferation, migration and invasion.

\section{Introduction}

Breast cancer is the most common malignant tumor among women worldwide and represents one of the major life threatening diseases in women (1). In 2019, 268,600 new cases of breast cancer were diagnosed and 41,760 women died from this disease in US (2). Breast cancer mostly occurs in women between the ages of 55 and 60 years (1). Long menstruation, no history of pregnancy, long-term use of hormonal contraceptives and obesity are the main factors contributing to breast cancer occurrence (1). Epidemiological studies reported that 
abnormal amplification of certain genes and mutations as well as genetic susceptibility modifications also serve crucial roles in the development of breast cancer $(3,4)$. It has been reported that $5-10 \%$ of breast cancer cases are due to genetic disorders, such as BRCA1 and BRCA2 mutations, which are associated with the hereditary breast-ovarian cancer syndrome (5). According to global statistics released by the International Agency for Research on Cancer in 2018, the incidence of breast cancer accounted for $11.6 \%$ of all cancers and represented the second most common cancer worldwide after lung cancer (6). In addition, breast cancer is a leading cause of cancer-associated mortality in women. In addition, the incidence of breast cancer has significantly grown worldwide, and has increased by $\sim 10$ times in the last decade (7). It is therefore urgent to determine some genes that could be associated with the proliferation, metastasis and apoptosis of breast cancer cells, in order to develop novel treatment.

With the continuous expansion of the Human Genome Project and the development of innovative technologies, including transcriptome and high-throughput gene sequencing, genetic mysteries have been gradually revealed. In 2012, the Encyclopedia of DNA Elements project has confirmed that non-coding RNAs are no longer RNAs of low interest, but are instead largely involved in numerous biological processes, including cell proliferation, differentiation and apoptosis (8). Long non-coding RNAs (lncRNAs) are defined as transcripts of $>200$ nucleotides in length that are not translated into proteins and that account for much of the transcribed genome. Previous studies reported that lncRNAs serve crucial roles in the development, diagnosis and treatment of certain types of tumor, including non-small cell lung cancer and colorectal cancer (9-12). Tissue differentiation inducing non-protein coding RNA (TINCR) is a key lncRNA of $\sim 3,700$ bp in length, which induces human epidermal differentiation following transcription (13). TINCR is a human skin disease-mutated gene, and its deletion can cause epidermal formation disorder (13). The mechanism of TINCR action is related to the binding of staufen1 (STAU1) protein and the stabilization of relevant differentiation genes mRNAs (14). It has been demonstrated that TINCR is abnormally expressed in a variety of malignant tumors, including gastric cancer (15), colon cancer (16), bladder cancer (17) and hepatocellular carcinoma (18), indicating that TINCT might be used as a biomarker for early tumor diagnosis. Gao et al (19) reported that the transcription factor SP1-induced upregulation of TINCR inhibits cell migration and invasion by regulating miR-107 and miR-1286 expression in lung adenocarcinoma. Furthermore, TINCR interacts with miR-335, and silencing TINCR inhibits epithelial ovarian cancer progression in vitro and in vivo by reducing fibroblast growth factor 2 expression (20). A meta-analysis demonstrated that TINCR overexpression might increase tumor size and worsen prognosis of patients with cancer (such as breast cancer and liver cancer) (21). In breast cancer, activation of TINCR by $\mathrm{H} 3 \mathrm{~K} 27$ acetylation promotes cell resistance to trastuzumab and epithelial-mesenchymal transition by targeting miR-125b (22). A previous study reported that upregulation of the competing endogenous RNA TINCR by transcription factor SP1 contributes to the tumorigenesis of breast cancer (23). Furthermore, the results from co-expression network analysis reported that TINCR expression is associated with breast cancer prognosis (24). By using the Gene Expression Omnibus (GEO) and The Cancer Genome Atlas (TCGA), it has been demonstrated that TINCR is significantly elevated in breast cancer cells (25). However, the underlying mechanisms remain unknown, and treatment for patients with breast cancer must be developed.

MicroRNAs (miRNAs) are a class of highly conserved single-stranded non-coding small RNAs that serve crucial roles in the growth and development of organisms (26). Although miRNAs account for only $\sim 2 \%$ of human genomes, they can regulate $\sim 21,000$ protein-coding genes (27). In-depth study of miRNAs will benefit cancer treatment and prognosis, by allowing early clinical diagnosis and therefore suggesting the most appropriate treatment for patients with breast cancer. Previous studies reported that TINCR can sponge certain miRNAs to promote cancer progression. For example, TINCR has been demonstrated to sponge miR-214-5p in order to upregulate Rho associated coiled-coil containing protein kinase 1 in hepatocellular carcinoma cells, leading therefore to the promotion cancer cell invasion and migration (18). Chen et al (28) reported that TINCR sponges miR-375 to upregulate pyruvate dehydrogenase kinase 1 that leads to gastric cancer progression. The present study used the breast cancer cell lines MCF-7 and MDA-MB-231 in order to explore the targeted relationship between TINCR and miR-589-3p, and to determine the underlying mechanism of miR-589-3p in breast cancer. The findings from this study may provide a reliable experimental basis for miRNA treatment of breast cancer.

\section{Materials and methods}

Cell culture. The MCF-7 (HTB-22) and MDA-MB-231 (HTB-26) cell lines used in the present study were purchased from the American Type Culture Collection. The cells were cultured in DMEM-H medium (cat. no. 12110-500; Beijing Solarbio Science \& Technology Co., Ltd.) containing $10 \%$ fetal bovine serum (FBS; cat. no. 0025; ScienCell Research Laboratories, Inc.) and placed at $37^{\circ} \mathrm{C}$ in a humidified incubator containing $5 \% \mathrm{CO}_{2}$.

Specimen collection form patients with breast cancer. Breast cancer and adjacent normal tissues of 68 patients with breast cancer (age range, 26-58 years; mean age, 42 years) treated at the Affiliated Zhongshan Hospital of Dalian University for breast surgery were collected between January 2012 and June 2018, whether they had received chemotherapy or not. Fresh specimens obtained during the surgery were immediately washed with physiological saline, frozen in liquid nitrogen and stored at $-80^{\circ} \mathrm{C}$. The present study has been approved by the Ethics Committee of Affiliated Zhongshan Hospital of Dalian University (approval no. 201112013RXW) and all patients signed informed consent.

Target gene prediction. The miRNAs targeted by TINCR were predicted by the StarBase database (http://starbase.sysu.edu. cn/index.php). TargetScan database (http://www.targetscan. org) was used to predict targeted genes for miRNAs.

Cell transfection. TINCR overexpression vector was constructed using pcDNA3.2 (cat. no. 12489019; Gibco; 
Thermo Fisher Scientific, Inc.). The primer sequences for PCR of TINCR cDNA were as follows: TINCR, forward 5'-CCCAAGCTTGGTCTGGGCTCCCAGGTGGACC-3' and reverse 5'-AGCGATATCCTATAGTTGTTTTCAAACATG TAATCTT-3'. After obtaining the full-length sequence of TINCR by reverse transcription-quantitative (RT-q)PCR, the TINCR gene was cloned into the pcDNA3.2 to obtain pc-TINCR. MCF-7 and MDA-MB-231 cells in the logarithmic growth stage were seeded in 6-well plates at the density of $2 \times 10^{5}$ cells/well one day prior to transfection. Cell transfection was performed when cells reached 70 80\% confluence by using Lipofectamine $^{\mathrm{TM}} 3000$ kit (cat. no. L3000015; Thermo Fisher Scientific, Inc.). Briefly, $1 \mu \mathrm{g}$ of pc-TINCR, pcDNA3.2 vector, TINCR small-interfering RNA (siTINCR; cat. no. SR316884; Origene), negative control siRNA (cat. no. SR30004; Origene), miR-589-3p mimic (cat. no. 4464066; Thermo Fisher Scientific, Inc.), miR-589-3p inhibitor (cat. no. 4464084, Thermo Fisher Scientific, Inc.), mimic control (cat. no. 4464058; Thermo Fisher Scientific, Inc.), inhibitor control (cat. no. 4464076; Thermo Fisher Scientific, Inc.), IGF1R (cat. no. RC214928; Origene) or IGF1R small interfering RNA (siIGF1R; cat. no. siB05109161217-1-5; RiboBio) were diluted in $50 \mu \mathrm{l}$ of Opti-MEM $^{\circledR}$ medium (cat. no. 31985062; Invitrogen; Thermo Fisher Scientific, Inc.). In addition, $3 \mu 1$ Lipofectamine $^{\mathrm{TM}} 3000$ reagent was diluted in $50 \mu \mathrm{l}$ Opti-MEM. The two solutions were then mixed together and were incubated for $15 \mathrm{~min}$ at room temperature. Subsequently, pc-TINCR, pcDNA3.2 vector, miR-589-3p mimic, mimic control or siIGF1R was added to MCF-7 cells seeded in a 6-well plate at the density of $5 \times 10^{5} /$ well $(500 \mu \mathrm{l})$. Furthermore, siTINCR, negative control siRNA, miR-589-3p inhibitor, inhibitor control or siIGF1R was added to MDA-MB-231 cells seeded in a 6-well plates at the density of $5 \times 10^{5} /$ well $(500 \mu \mathrm{l})$. In addition, MCF-7 cells were co-transfected with pc-TINCR and miR-589-3p mimic, or IGF1R and miR-589-3p mimic. MDA-MB-231 cells were also co-transfected with siTINCR and miR-589-3p inhibitor, or siIGF1R and miR-589-3p inhibitor. Expression of TINCR, miR-589-3p and IGF1R was measured after $24 \mathrm{~h}$ transfection.

Luciferase assay. PmirGLO reporter plasmids (cat. no. CL414-01; Biomed) containing wild type TINCR (TINCR-wt) or mutant TINCR (TINCR-mut), or wild type IGF1R (IGF1R-wt) or mutant IGF1R (IGF1R-mut) were constructed. MCF-7 and MDA-MB-231 cells in logarithmic growth phase were washed twice with PBS, and harvested by using $6 \mathrm{ml} 0.25 \%$ trypsin (cat. no. 25200072; Invitrogen; Thermo Fisher Scientific, Inc.) from a $10-\mathrm{cm}$ culture dish. Once cells were evenly distributed into the dish, the culture was terminated by adding medium containing $15 \%$ fetal calf serum (cat. no. C0251; Beyotime Institute of Biotechnology). Cells were seeded in 6 -well plates at the density of $5 \times 10^{5}$ cells/well and placed in an incubator at $37^{\circ} \mathrm{C}$. After $24 \mathrm{~h}$, the co-transfection was initiated by adding $50 \mathrm{ng}$ pmirGLO plasmid and 100 pmol miR-589-3p mimic (or miR-589-3p mimic control) in each well. After $48 \mathrm{~h}$, luciferase activity was detected by using the dual-luciferase reporter kit (cat. no. 16184; Thermo Fisher Scientific, Inc.). After aspirating the culture medium, cells were washed once by PBS. Subsequently, $500 \mu 1$ PLB was added to the cells that were gently shaken for $15 \mathrm{~min}$ at room temperature. Firefly luciferase activity (firefly) was measured after adding $100 \mu 1$ LARII to $20 \mu 1$ sample lysate. Eventually, $100 \mu$ l Stop\&Glo reagent was added to the mixture and the activity of Renilla luciferase was detected by using the luminometer GloMax ${ }^{\circledR}$ 20/20 (Promega Corporation). The experimental results were obtained by calculating the ratio of firefly/renilla.

Total RNA extraction from tissues and cells and RT-qPCR. Total RNA was extracted from tissues and cells by using TRIzol $^{\mathrm{TM}}$ reagent (cat. no. 15596-026; Invitrogen; Thermo Fisher Scientific, Inc.). Briefly, frozen tissues were sliced into pieces and placed in a centrifuge tube and TRIzol ${ }^{\mathrm{TM}}$ reagent $(1 \mathrm{ml})$ was added. The mixture was grounded in a TissuePrep homogenizer (Gering Scientific Instruments) for $5 \mathrm{~min}$ at 30 times $/ \mathrm{sec}$ and was centrifuged for $10 \mathrm{~min}\left(4^{\circ} \mathrm{C}\right.$; $1,600 \mathrm{x} \mathrm{g}$ ). The supernatant was collected, mixed with $200 \mu \mathrm{l}$ chloroform and centrifuged for $10 \mathrm{~min}\left(4^{\circ} \mathrm{C} ; 1,600 \mathrm{x}\right.$ g) again. The supernatant was mixed with $500 \mu \mathrm{l}$ isopropyl alcohol and a white precipitate was obtained following centrifugation for $10 \mathrm{~min}\left(4^{\circ} \mathrm{C} ; 1,600 \mathrm{xg}\right)$. The precipitate was washed twice with $75 \%$ ethanol and was dissolved by adding $20 \mu \mathrm{l}$ diethyl pyrocarbonate (DEPC)-treated water (cat. no. 750023; Thermo Fisher Scientific, Inc.) in order to obtain the total RNA. Total RNA was extracted from breast cancer cells by using TRIzol ${ }^{\mathrm{TM}}$ reagent according to the manufacturers' instructions. Subsequently, RNA concentration was measured by using a NanoDrop2000 (cat. no. YQ1633128263; Thermo Fisher Scientific, Inc.). RNA was reverse transcribed according to the manufacturers' protocol. The RNAs of TINCR, IGF1R, AKT and GAPDH (internal reference) were reverse transcribed by using RevertAid First Strand cDNA Synthesis kit (cat. no. k1622; Thermo Fisher Scientific, Inc.). The RNA of miR-589-3p was formulated by using All-in-One ${ }^{\mathrm{TM}}$ miRNA First-Strand cDNA Synthesis kit (cat. no. QP013; GeneCopoeia, Inc.) and $\mathrm{TaqMan}^{\mathrm{TM}}$ Universal PCR Master Mix (cat. no. 4304437; $\mathrm{ABI}$ ). U6 served as an internal reference. The reaction mixture for RT-qPCR contained $2 \mu \mathrm{l}$ cDNA (diluted 10-fold), $1 \mu \mathrm{l}$ of forward and reverse primers at $10 \mu \mathrm{M}, 6 \mu \mathrm{l}$ DEPC-treated water and $10 \mu 1$ FastStart Universal SYBR Green Master (cat. no. 0491391400; Roche Diagnostics). RT-qPCR reactions were performed as follows: Pre-denaturation at $95^{\circ} \mathrm{C}$ for $10 \mathrm{~min}$, denaturation at $95^{\circ} \mathrm{C}$ for $15 \mathrm{sec}$, annealing at $60^{\circ} \mathrm{C}$ for $1 \mathrm{~min}$, for a total of 40 cycles. The relative expression levels were normalized to endogenous controls and were expressed as $2^{-\Delta \Delta C q}(29)$. The sequences of the primers used were as follows: TINCR, forward 5'-CCCAAGCTTGGTCTG GGCTCCCAGGTGGACC-3', reverse 5'-AGCGATATCCTA TAGTTGTTTTCAAACATGTAATCTT-3'; IGF1R, forward 5'-TGCGTGAGAGGATTGAGTTTC-3', reverse 5'-CTTATT GGCGTTGAGGTATGC-3'; AKT, forward 5'-TGTGGATTT ACCTTATCCCCTCA-3', reverse 5'-GTTTGGCTTTGG TCGTTCTGT-3'; GAPDH, forward 5'-TGTGGGCATCAA TGGATTTGG-3', reverse 5'-ACACCATGTATTCCGGGT CAAT-3'; miR-589-3p, forward 5'-AACAAATGCCGGTTC CCAGA-3', reverse 5'-TGTCGTGGAGTCGGCAATTG-3'; and U6, forward 5'-TCTGCTCCTATCCCAATTACCTG-3' and reverse 3'-ACTCCCGGATCTCTTCTAAGTTG-3'.

Patients survival analysis. A monthly follow-up was conducted on the 68 patients with breast cancer up to five years. The 
survival rate was calculated by using the Kaplan-Meier cumulative survival curve.

Cell proliferation. MCF-7 and MDA-MB-231 cell proliferation was detected by using MTT reagent (cat. no. ST316; Beyotime Institute of Biotechnology). Briefly, cells in the logarithmic growth phase were harvested by using $0.25 \%$ trypsin. The cell concentration was adjusted to $5 \times 10^{3}$ cells/well, and $100 \mu \mathrm{l}$ suspension was seeded in a 96 -well plate and incubated at $37^{\circ} \mathrm{C}$ for $48 \mathrm{~h}$. Subsequently, supernatant was removed, and $90 \mu \mathrm{l}$ culture medium and $10 \mu 1$ MTT reagent were added to each well. After $4 \mathrm{~h}$ incubation, supernatant was aspirated, $100 \mu \mathrm{l}$ DMSO was added to each well and the plate was gently shaken for $10 \mathrm{~min}$ to fully dissolve formazan crystals. Absorbance was read at $490 \mathrm{~nm}$ on a microplate reader.

Cell apoptosis. Flow cytometry was used to detect the apoptosis of MCF-7 and MDA-MB-231 cells following transfection with different plasmids. Cells in the logarithmic growth phase were washed three times with PBS, harvested by using $0.25 \%$ trypsin, collected and centrifuged for $5 \min \left(1,000 \mathrm{x} \mathrm{g}\right.$, at $\left.4^{\circ} \mathrm{C}\right)$. MCF-7 and MDA-MB-231 cells were washed twice with PBS and centrifuged for $5 \mathrm{~min}\left(1,000 \mathrm{x} \mathrm{g} ; 4^{\circ} \mathrm{C}\right)$, and then incubated with $5 \mu$ l Annexin V-FITC (cat. no. KGA108; Nanjing KeyGen Biotech Co., Ltd.) and $10 \mu l$ propidium iodide solution (cat. no. C1062M; Beyotime Institute of Biotechnology) for $20 \mathrm{~min}$ at room temperature in the dark. Cell apoptosis was detected by flow cytometry (cat. no. 322457; Bio-Rad Laboratories, Inc.) and data analysis was performed using FACSdiva software version 6.1.2 (BD Biosciences).

Wound healing assay. A marker was used to evenly draw a $0.5 \sim 1 \mathrm{~cm}$ horizontal line under the 6-well plate. MCF-7 and MDA-MB-231 cells in the logarithmic growth phase were seeded at the density of $5 \times 10^{5}$ cells/well and incubated overnight. The next day, the tip of a pipette was used to scratch the cell layer, and cells were washed three times with PBS. Serum-free medium was added and cells were cultured at $37^{\circ} \mathrm{C}$ with $5 \% \mathrm{CO}_{2}$ for $48 \mathrm{~h}$. Cell migration was imaged using a light microscope (magnification, $\mathrm{x} 100$ ) at 0 and $48 \mathrm{~h}$.

Cell invasion assay. Transwell chambers $(8-\mu \mathrm{m}$ pore size; BD Biosciences) were used to detect the invasion ability of MCF-7 and MDA-MB-231 cells. The two cell lines were serum-starved for $12 \mathrm{~h}$ and harvested by using $0.25 \%$ trypsin. Cells were seeded at the density of $1 \times 10^{4}$ cells/per well in the upper chamber of the Transwell that was pre-coated with Matrigel (cat. no. YZ-354234; Beijing Solarbio Science \& Technology Co., Ltd.), and DMEM containing 10\% FBS was added to the lower chamber. Following $48 \mathrm{~h}$ incubation, cells that have invaded the bottom membrane were fixed with $4 \%$ paraformaldehyde for $15 \mathrm{~min}$ at room temperature and stained by $0.1 \%$ crystal violet stain. Cell invasion was observed under a light microscope (magnification, x200) and the cell number was counted by Image $\mathbf{J}$ software (version 1.8.0; National Institutes of Health).

Western blotting. Proteins were extracted from MCF-7 and MDA-MB-231 cells. Cells were lysed using RIPA (cat. no. 89900; Thermo Fisher Scientific, Inc.). Cell lysate was centrifuged at $1,600 \mathrm{x} \mathrm{g}, 4^{\circ} \mathrm{C}$ for $10 \mathrm{~min}$. The supernatant was collected and protein concentration was measured using the BCA Protein Assay kit (cat. no. 23227; Thermo Fisher Scientific, Inc.). Proteins ( $25 \mu \mathrm{g})$ were separated by $12 \%$ SDS-PAGE and transferred onto PVDF membranes (cat. no. RPN303F; GE Healthcare). Membranes were washed three times with TBST (cat. no. T1085; Beijing Solarbio Science \& Technology Co., Ltd.) and blocked with a blocking buffer containing $5 \%$ bovine serum albumin (cat. no. SW3015-500 ml; Beijing Solarbio Science $\&$ Technology Co., Ltd.) for $2 \mathrm{~h}$ at room temperature. Membranes were incubated with primary antibodies against IGF1R (cat. no. ab39675; 155 KD; 1:1,000; Abcam), phosphor (p)-Akt (cat. no. ab38449; 56 kD; 1:1,000; Abcam), Akt (cat. no. ab8805; 55 kD; 1:500; Abcam), GAPDH (internal control; cat. no. ab8245; $36 \mathrm{KD}$; 1:10,000, Abcam) overnight at $4^{\circ} \mathrm{C}$. Membranes were washed three times with TBST and incubated with the goat anti-rabbit IgG secondary antibody (cat. no. ab6721, 1:10,000, Abcam) for $1 \mathrm{~h}$ at room temperature. Immobilon Western Chemiluminescent HRP Substrate (cat. no. WBKLS0100; Merck KGaA) was used to detect the signal on the membrane. Bands were imaged by using the Gel Imager System (1708265, Bio-Rad) and data were analyzed via densitometry using ImageJ software (version 1.46) and normalized to expression of the internal control.

Statistical analysis. Data were analyzed using SPSS 23.0 software (IBM Corp.) and were expressed as the means \pm standard deviation of the mean. Student's two-tailed t-test was used to compare differences between two groups. ANOVA followed by Turkey test was used to compare differences between $\geq 3$ groups. Correlation analysis was preformed using Spearman correlation coefficient algorithm. $\mathrm{P}<0.05$ was considered to indicate a statistically significant difference.

\section{Results}

TINCR overexpression in breast cancer tissues is negatively correlated with miR-589-3p expression. A targeted relationship between TINCR and miR-589-3p was predicted by Starbase and results from luciferase assay (Fig. 1A-C). To examine the role of TINCR and miR-589-3p in breast cancer, the expression level of TINCR and miR-589-3p in breast cancer tissues was determined by RT-qPCR (Fig. 1D and E). The results demonstrated that TINCR expression level was significantly higher in breast cancer tissues compared with adjacent tissues $(\mathrm{P}<0.001)$; however, miR-589-3p expression level was significantly lower in cancer tissues compared with normal tissues $(\mathrm{P}<0.001)$. Furthermore, the results demonstrated that TINCR and miR-589-3p expression levels were negatively correlated (Fig. 1G; $r=-0.331 ; \mathrm{P}=0.006$ ). According to the mean as the segmentation point, the expression of miR-589-3p was divided into high expression and low expression. In addition, the results from Kaplan-Meier overall survival curves demonstrated that patients with high TINCR expression level had a lower survival rate at five years $(\mathrm{P}<0.05$; Fig. $1 \mathrm{~F})$.

TINCR overexpression downregulates miR-589-3p expression in breast cancer cells. The regulatory relationship between TINCR and miR-589-3p was further investigated by RT-qPCR. The results demonstrated that cell transfection 


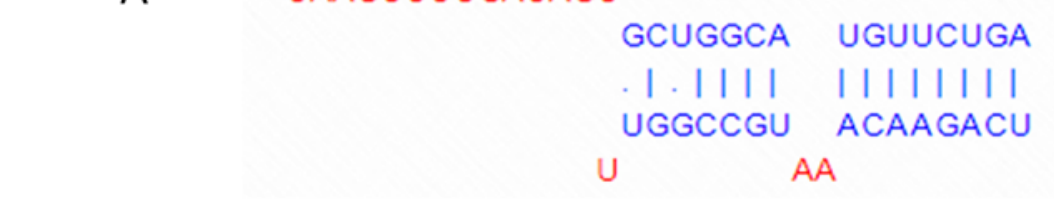

B

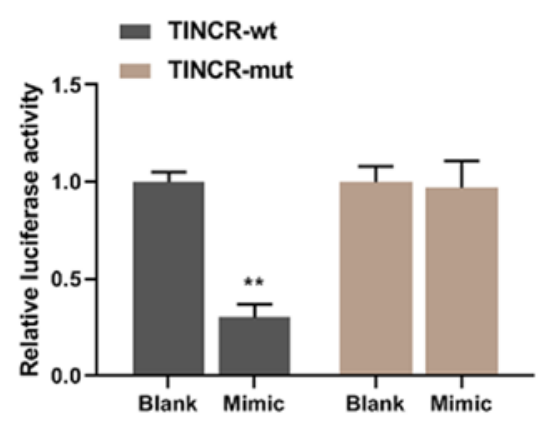

D

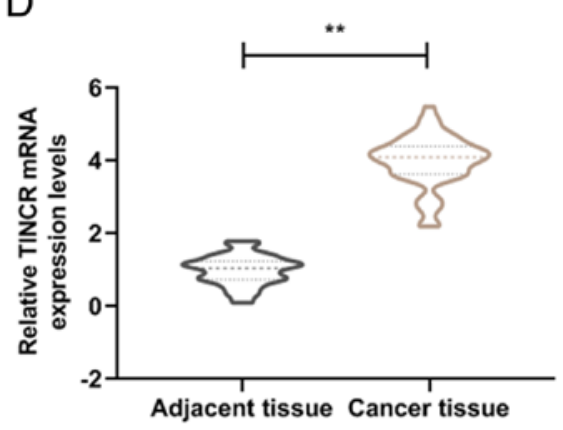

$\mathrm{F}$

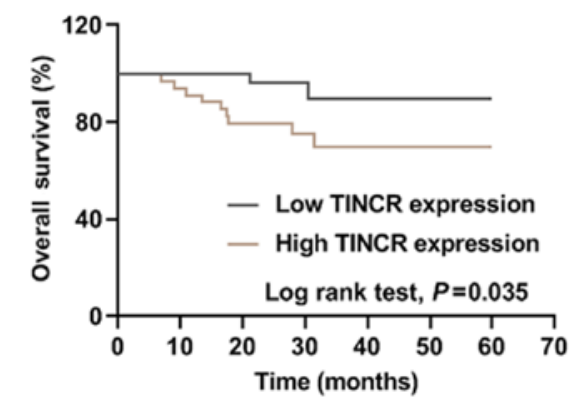

C MDA-MB-231

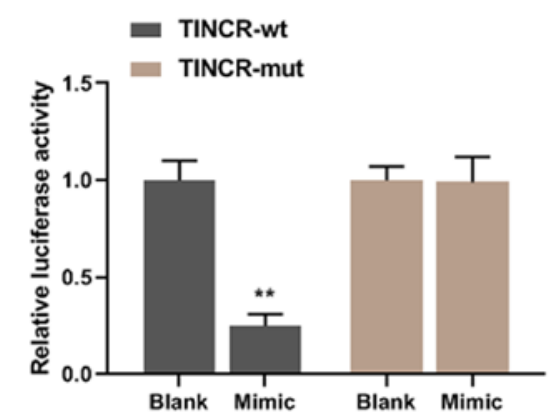

E

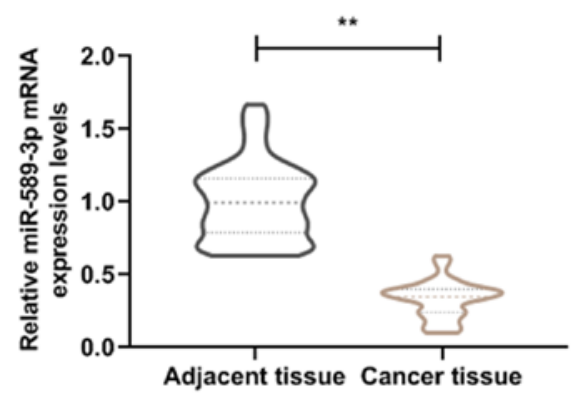

G

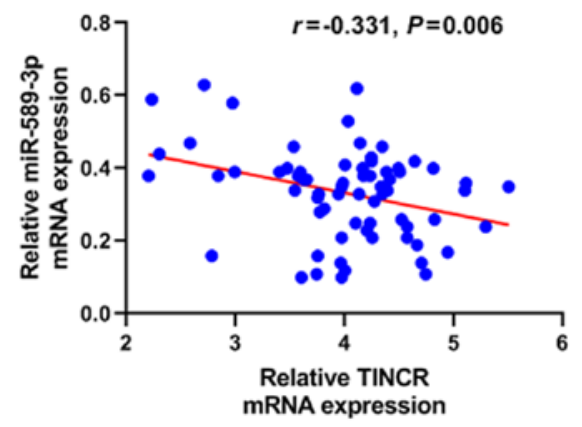

Figure 1. TINCR was highly expressed in breast cancer tissues and was negatively correlated with miR-589-3p expression level. (A) TINCR targeting miRNA was predicted by StarBase. (B and C) Luciferase activity of TINCR in miR-589-3p mimic group was detected by luciferase assay. ${ }^{* *} \mathrm{P}<0.01 \mathrm{vs}$. blank. (D) RT-qPCR was used to detect TINCR expression level in breast cancer and adjacent tissues ( $\mathrm{n}=68$ ). GAPDH was used as the internal reference. (E) RT-qPCR was used to detect miR-589-3p expression level in breast cancer and adjacent tissues $(\mathrm{n}=68)$. U6 was used as the internal reference. ${ }^{* *} \mathrm{P}<0.01$ vs. adjacent tissues. (F) Kaplan-Meier curve analysis of the 5-year survival curve of all patients with breast cancer ( $\mathrm{n}=68$ ). (G) Correlation between TINCR and miR-589-3p expression levels. All experiments were repeated three times. miR, microRNA; mut, mutant; RT-qPCR, reverse transcription-quantitative PCR; TINCR, tissue differentiation inducing non-protein coding RNA; wt, wild type.

with miR-589-3p mimic and inhibitor did not affect TINCR expression (Fig. 2A and B); however, the effect of pc-TINCR on miR-589-3p expression was reversed by miR-589-3p mimic $(\mathrm{P}<0.001$; Fig. 2C). Furthermore, miR-589-3p inhibitor reversed miR-589-3p expression level that was promoted by silencing TINCR ( $\mathrm{P}<0.001$; Fig. 2D). These results suggested that TINCR may be able to downregulate miR-589-3p, which may be reversed by miR-589-3p mimic.

miR-589-3p mimic partially reverses the promoting and inhibiting effects of TINCR on breast cancer cell proliferation and apoptosis, respectively. The effect of TINCR on breast cancer cell proliferation and apoptosis was investigated. The results demonstrated that pc-TINCR promoted MCF-7 cell proliferation $(\mathrm{P}<0.001$; Fig. 3A) and inhibited MCF-7 cell apoptosis $(\mathrm{P}<0.001$; Fig. $3 \mathrm{C}$ and $\mathrm{D})$; however, siTINCR significantly inhibited MDA-MB-231 cell proliferation $(\mathrm{P}<0.001$; Fig. 3B) and promoted cell apoptosis $(\mathrm{P}<0.001$; Fig. $3 \mathrm{E}$ and $\mathrm{F})$. These findings suggested that TINCR could promote breast cancer cell proliferation and inhibit their apoptosis. In addition, further results demonstrated that miR-589-3p mimic reversed the effect of pc-TINCR on breast cancer cell proliferation 
A

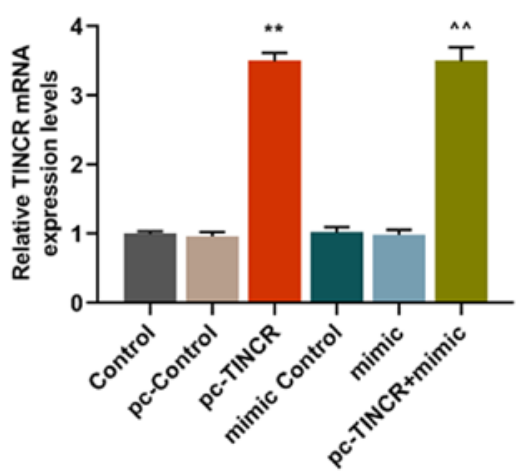

C

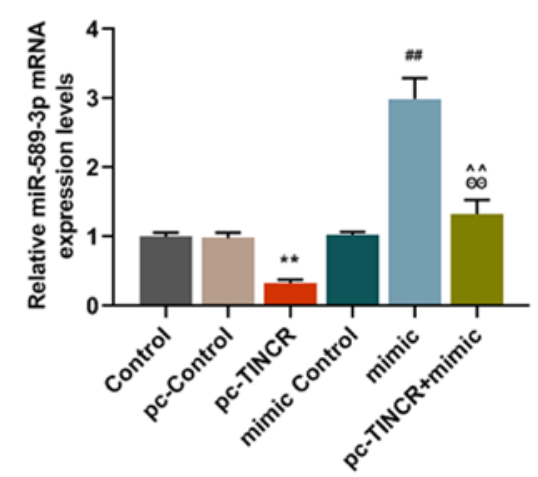

B

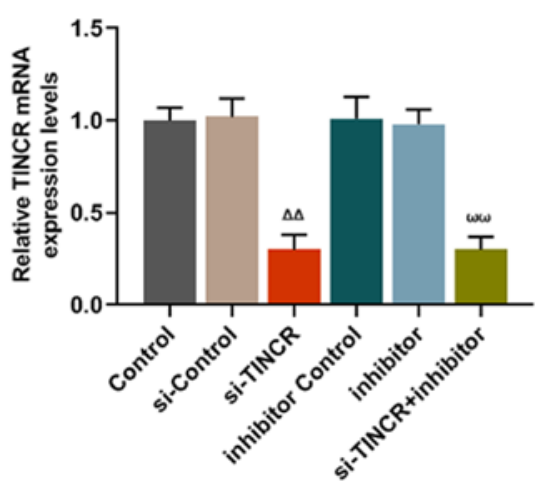

MDA-MB-231

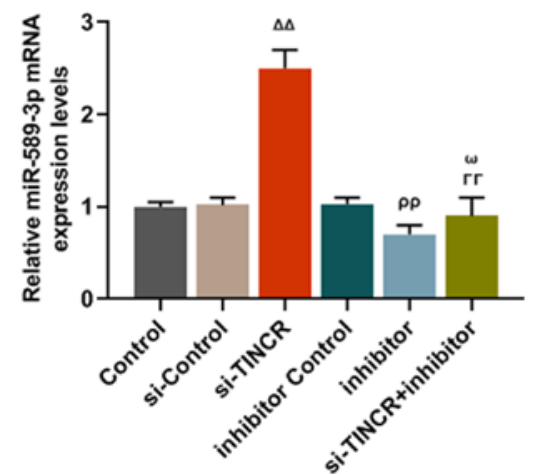

Figure 2. miR-589-3p mimic reversed the effect of TINCR overexpression on miR-589-3p expression. (A and B) RT-qPCR was used to detect TINCR expression level in transfected MCF-7 and MDA-MB-231 cells. GAPDH was used as an internal reference. (C and D) RT-qPCR was used to detect the expression level of miR-589-3p in transfected MCF-7 and MDA-MB-231 cells. U6 was used as an internal reference. All experiments were repeated three times. ${ }^{* *} \mathrm{P}<0.01 \mathrm{vs}$. pc-Control; ${ }^{\# \#} \mathrm{P}<0.01$ vs. miR-589-3p mimic control; ${ }^{\Theta} \mathrm{P}<0.001$ vs. pc-TINCR; ${ }^{\wedge} \mathrm{P}<0.01$ vs. miR-589-3p mimic; ${ }^{\Delta \Delta} \mathrm{P}<0.01$ vs. si-Control; ${ }^{\omega} \mathrm{P}<0.05$ and ${ }^{\omega \omega} \mathrm{P}<0.01$ vs. miR-589-3p inhibitor; ${ }^{\rho \rho} \mathrm{P}<0.01$ vs. miR-589-3p inhibitor control; ${ }^{\Gamma \Gamma} \mathrm{P}<0.01$ vs. si-TINCR. miR, microRNA; RT-qPCR, reverse transcription-quantitative PCR; TINCR, tissue differentiation inducing non-protein coding RNA; si, small interfering.

$(\mathrm{P}<0.001$; Fig. 3A) and inhibited cell apoptosis $(\mathrm{P}<0.001$; Fig. 3C and D). Furthermore, miR-589-3p inhibitor reversed the effect of siTINCR on breast cancer cell proliferation and apoptosis $(\mathrm{P}<0.001$; Fig. 3B, E and F). These data indicated that the effects of TINCR on the promotion and the inhibition of breast cancer cell proliferation and apoptosis, respectively, may be reversed by miR-589-3p mimic.

miR-589-3p mimic partially reverses the promoting effect of TINCR on the migratory and invasive abilities of breast cancer cells. The effect of TINCR and miR-589-3p mimic on the migratory and invasive abilities of breast cancer cells was examined. The results from the wound healing assay demonstrated that the migratory rate of breast cancer cells in the pc-TINCR group was significantly increased compared with the pc-control group $(\mathrm{P}<0.001$; Fig. $4 \mathrm{~A}$ and $\mathrm{B})$. The results from Transwell assay demonstrated that the invasive ability of breast cancer cells the pc-TINCR group was significantly increased compared with the pc-control group $(\mathrm{P}<0.001$; Fig. 4E and F); however, siTINCR transfection had the opposite effects $(\mathrm{P}<0.001$; Fig. 4C, D, G and $\mathrm{H})$. In addition, the results demonstrated that miR-589-3p mimic partially reversed the effects of pc-TINCR on the migratory and invasive abilities of breast cancer cells ( $\mathrm{P}<0.001 ;$ Fig. 4A, B, E and F). Furthermore, miR-589-3p inhibitor also partially reversed the inhibiting effects of siTINCR on the migratory and invasive abilities of breast cancer cells ( $\mathrm{P}<0.001$; Fig. $4 \mathrm{C}, \mathrm{D}, \mathrm{G}$ and $\mathrm{H})$. These findings suggested that TINCR may promote breast cancer cell migratory and invasive abilities; however, these effects may by partially reversed by miR-589-3p mimic.

$I G F 1 R$ is a target gene of $m i R-589-3 p$. The results from TargetScan database revealed that IGF1R had a binding site to miR-589-3p at the 3'UTR position (Fig. 5A), indicating that IGF1R may be considered as a target gene for miR-589-3p. For further validation, luciferase assay was performed and the results demonstrated that IGF1R luciferase activity in the miR-589-3p mimic group was lower compared with the control group $(\mathrm{P}<0.001$; Fig. $5 \mathrm{~B}$ and $\mathrm{C})$ in both breast cancer cell lines. Not only IGF1R was a target gene of miR-589-3p but it may also be downregulated by miR-589-3p mimic.

miR-589-3p mimics can partially reverse the effects of IGFIR on cell proliferation, migration, invasion and apoptosis. Proliferation, apoptosis, and migratory and invasive abilities of breast cancer cells were detected. The results demonstrated that IGF1R significantly promoted the proliferation, migration and invasion of MCF-7 cells ( $\mathrm{P}<0.001$; Figs. 5D, 6A and B, E and F); however, these effects were partially reversed by miR-589-3p mimic $(\mathrm{P}<0.001$; Figs. 5D, 6A and B, E and F). Furthermore, 
A

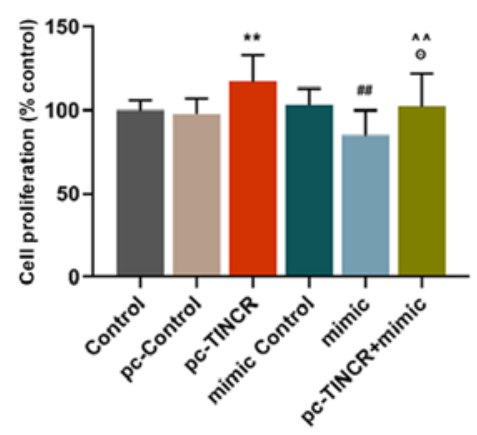

C

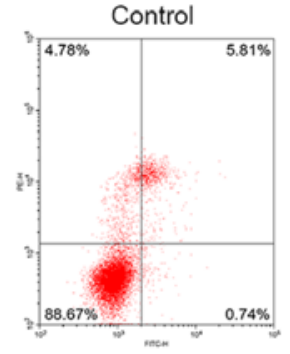

D

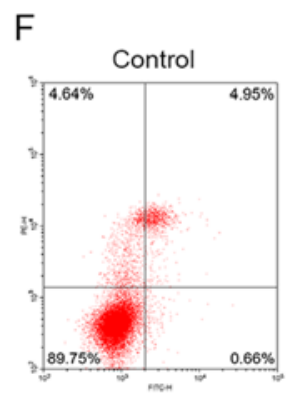

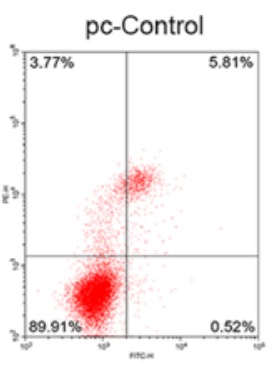

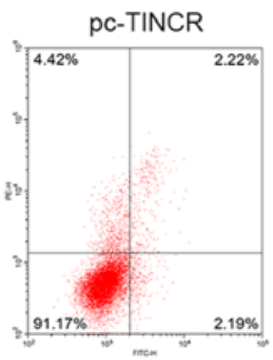

MCF-7
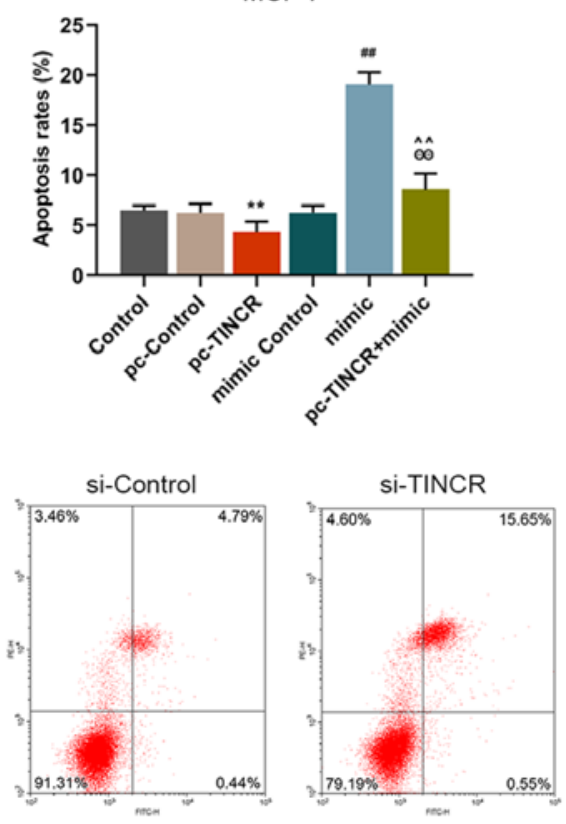

B

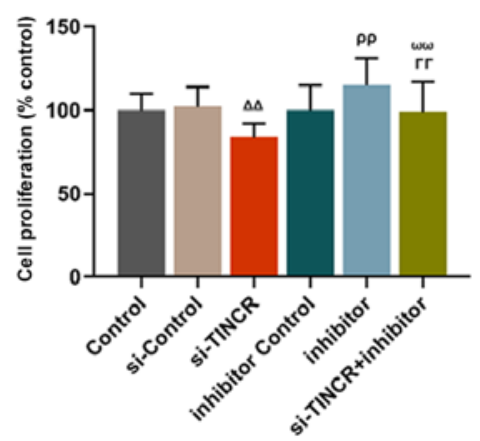

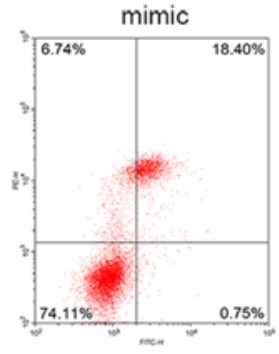

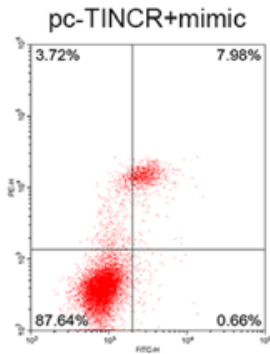

$\mathrm{E}$
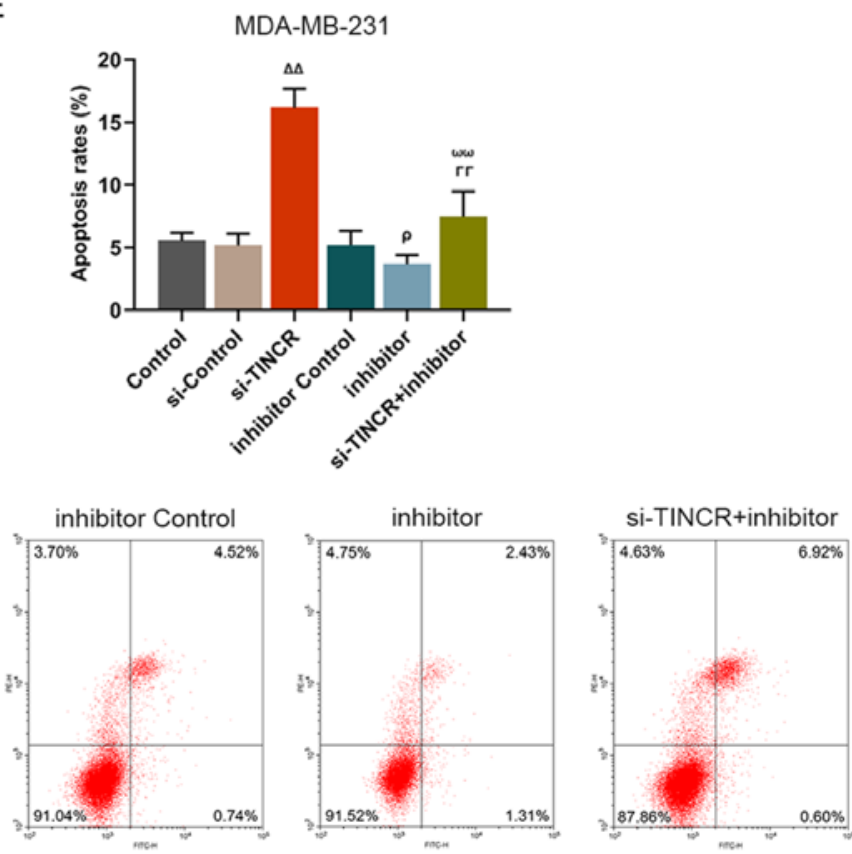

Figure 3. miR-589-3p mimic partially reversed the effect of TINCR overexpression on the promotion and inhibition of breast cancer cell proliferation and apoptosis, respectively. (A and B) MTT assay was used to detect MCF-7 and MDA-MB-231 cell proliferation. (C-F) Flow cytometry was used to detect MCF-7 and MDA-MB-231 cell apoptosis. All experiments were repeated three times. ${ }^{* *} \mathrm{P}<0.01 \mathrm{vs.} \mathrm{pc-Control;}{ }^{\# \#} \mathrm{P}<0.01$ vs. miR-589-3p mimic control; ${ }^{\Theta} \mathrm{P}<0.05$ and ${ }^{\Theta \Theta} \mathrm{P}<0.01$ vs. pc-TINCR; ${ }^{\wedge} \mathrm{P}<0.01$ vs. miR-589-3p mimic; ${ }^{\Delta \Delta} \mathrm{P}<0.001$ vs. si-Control; ${ }^{\omega \omega} \mathrm{P}<0.01$ vs. miR-589-3p inhibitor; ${ }^{\circ} \mathrm{P}<0.05$, ${ }^{\rho} \mathrm{P}<0.01$ vs. miR-589-3p inhibitor control; ${ }^{\Gamma \Gamma} \mathrm{P}<0.01$ vs. si-TINCR. miR, microRNA; TINCR, tissue differentiation inducing non-protein coding RNA; si, small interfering.

IGF1R silencing inhibited MDA-MB-231 cell proliferation, migration and invasion ( $\mathrm{P}<0.001$; Figs. 5E, $6 \mathrm{C}$ and $\mathrm{D}, \mathrm{G}$ and $\mathrm{H})$, which was reversed by miR-589-3p inhibitor. In addition, the results from flow cytometry demonstrated that the inhibitory effect of IGF1R on the apoptosis of MCF-7 cells was reversed by miR-589-3p mimic $(\mathrm{P}<0.001$; Fig. $5 \mathrm{~F})$, and the promoting effects of siIGF1R on MDA-MB-231 cell apoptosis were reversed by miR-589-3p inhibitor $(\mathrm{P}<0.001$; Fig. $5 \mathrm{G})$. These findings demonstrated that IGF1R may promote cell proliferation, migration and invasion, and inhibit cell apoptosis; however these effects may be partially reversed by miR-589-3p mimic.
miR-589-3p can downregulate IGFIR and Akt protein expression in breast cancer cells. The underlying mechanism of miR-589-3p in breast cancer cells was investigated by RT-qPCR and western blotting. The mRNA expression of IGF1R and Akt (Fig. 7A and B) was detected by RT-qPCR. The results demonstrated that IGF1R expression was downregulated following co-transfection with IGFR1 and miR-589-3p mimic compared with IGF1R group $(\mathrm{P}<0.001)$, whereas IGF1R expression was significantly upregulated following co-transfection with siIGF1R and miR-589-3p inhibitor compared with siIGF1R group $(\mathrm{P}<0.001)$. No change in Akt expression 
A

pc-Control

PC-TINCR

mimic Control

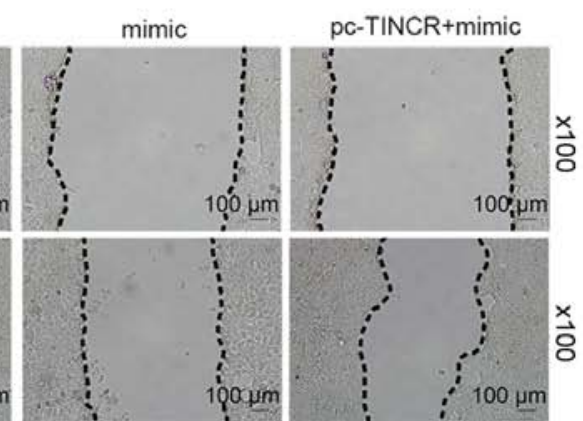

B
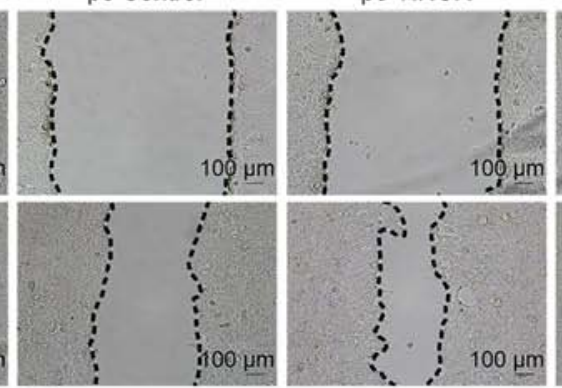

MCF-7

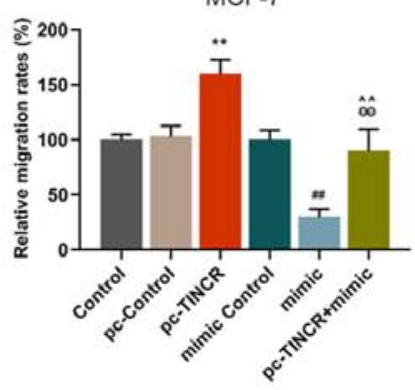

C

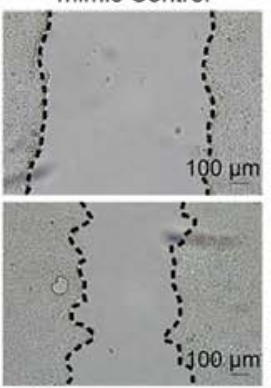

MDA-MB-231

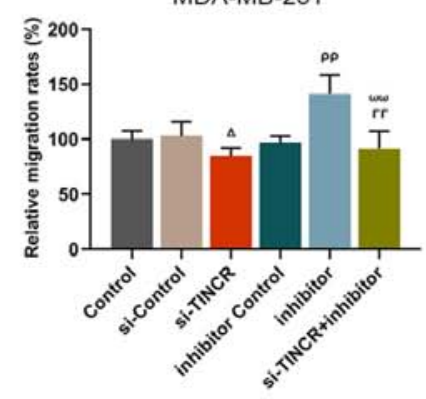

D

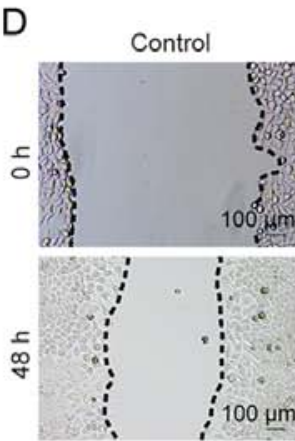

si-Control

Si-TINCR

inhibitor Control
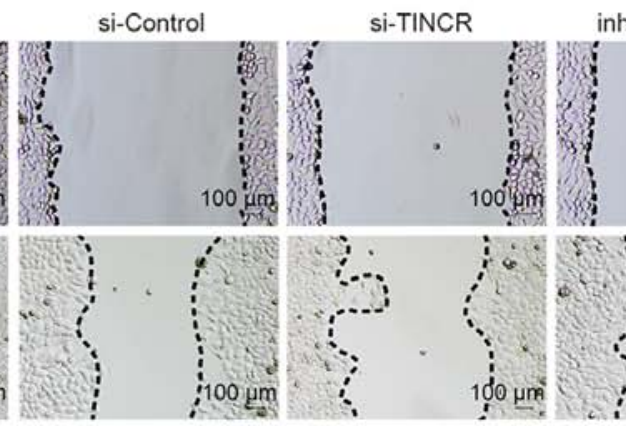

inhibitor
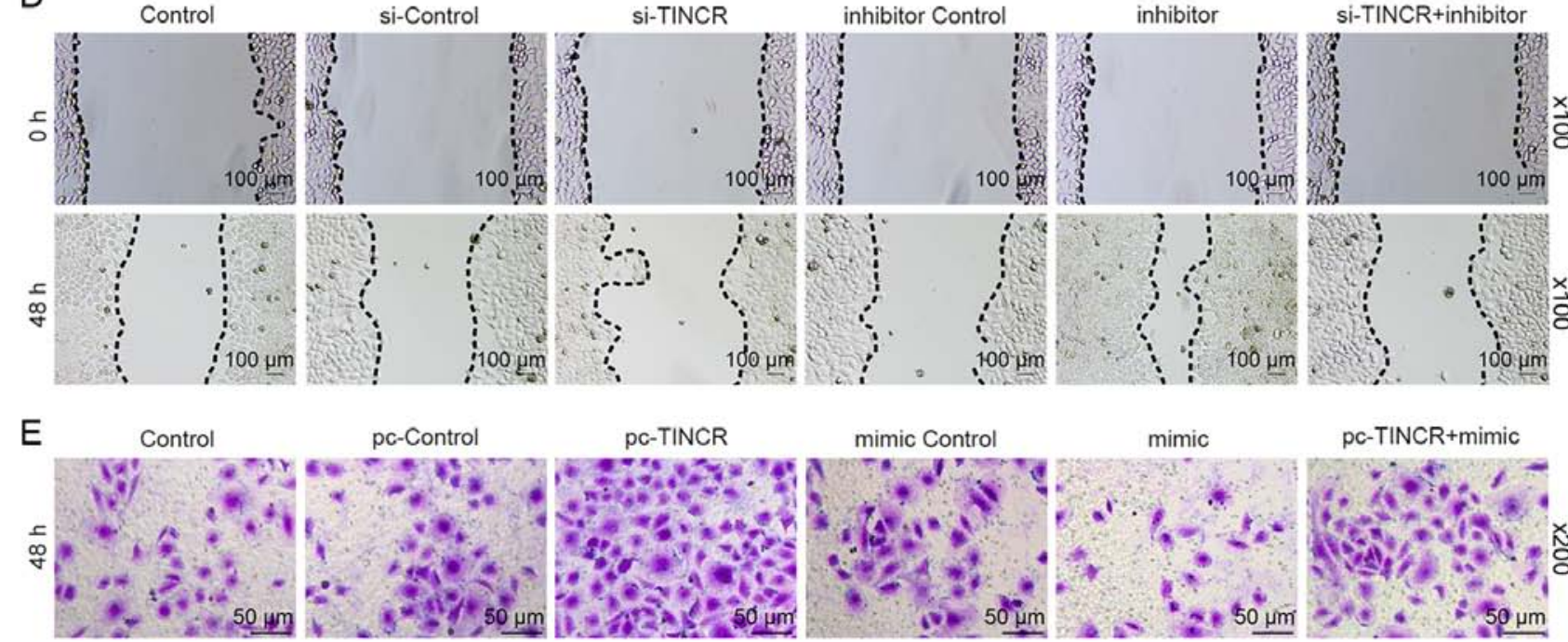

pc-TINCR+mimic

$\mathrm{F}$

MCF-7

G

MDA-MB-231
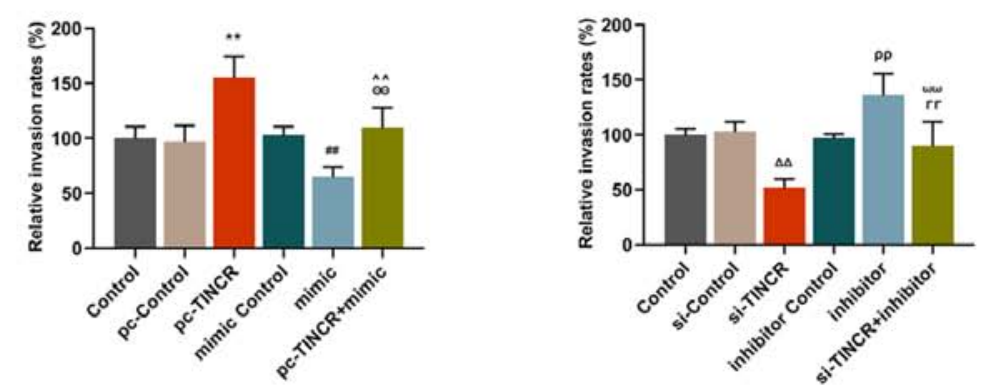

$\mathrm{H}$
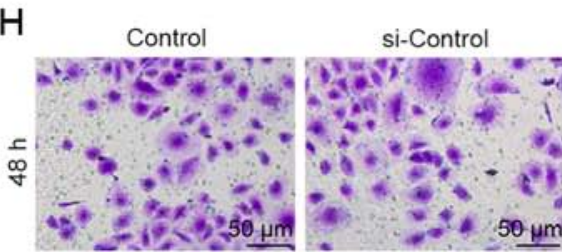

Si-TINCR

inhibitor Control

inhibitor

si-TINCR+inhibitor

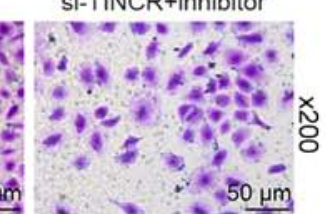

Figure 4. miR-589-3p mimic could partially reverse the effect of TINCR overexpression on breast cancer cell migratory and invasive abilities. (A-D) Wound healing assay detected the migratory ability of MCF-7 and MDA-MB-231 cells. (E-H) Invasive ability of MCF-7 and MDA-MB-231 cells detected by Transwell assay. All experiments were repeated three times. ${ }^{* *} \mathrm{P}<0.01 \mathrm{vs.} \mathrm{pc-Control;}{ }^{\# \#} \mathrm{P}<0.01 \mathrm{vs.} \mathrm{miR-589-3p} \mathrm{mimic} \mathrm{control;}{ }^{\Theta \Theta} \mathrm{P}<0.01$ vs. pc-TINCR; ${ }^{\wedge} \mathrm{P}<0.01$ vs. miR-589-3p mimic; ${ }^{\Delta} \mathrm{P}<0.05$ and ${ }^{\Delta \Delta} \mathrm{P}<0.01$ vs. si-Control; ${ }^{\omega \omega} \mathrm{P}<0.01$ vs. miR-589-3p inhibitor; ${ }^{\rho \rho} \mathrm{P}<0.01$ vs. miR-589-3p inhibitor control; ${ }^{\Gamma \Gamma} \mathrm{P}<0.01 \mathrm{vs}$. si-TINCR. miR, microRNA; TINCR, tissue differentiation inducing non-protein coding RNA; si, small interfering. 
A

\begin{tabular}{|c|c|}
\hline & $\begin{array}{l}\text { Predicted consequential pairing of target region (top) } \\
\text { and miRNA (bottom) }\end{array}$ \\
\hline $\begin{array}{l}\text { Position 3062-3068 of IGF1R } 3 \text { UTR } \\
\text { hsa-miR-589-3p }\end{array}$ & $\begin{array}{l}\text { W. GCAGUGGUUCCUCAGGUUCUGAG.. } \\
\text { IIIIIII } \\
\text { AGACCCUUGGCCGUARCAAGACU }\end{array}$ \\
\hline
\end{tabular}

B

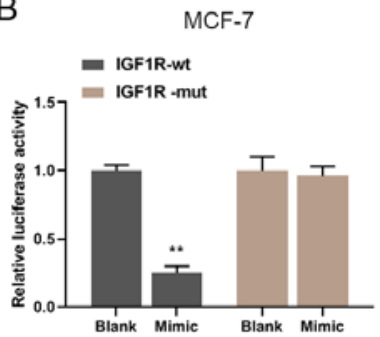

C

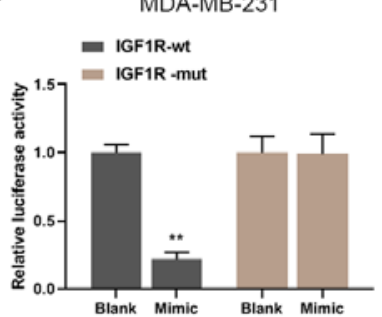

D

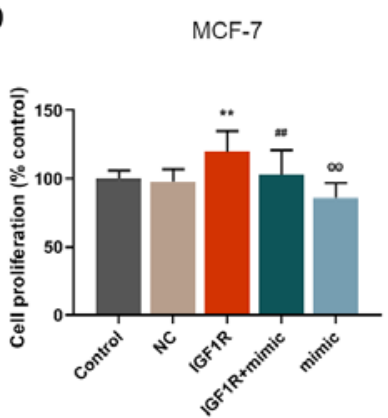

$\mathrm{F}$
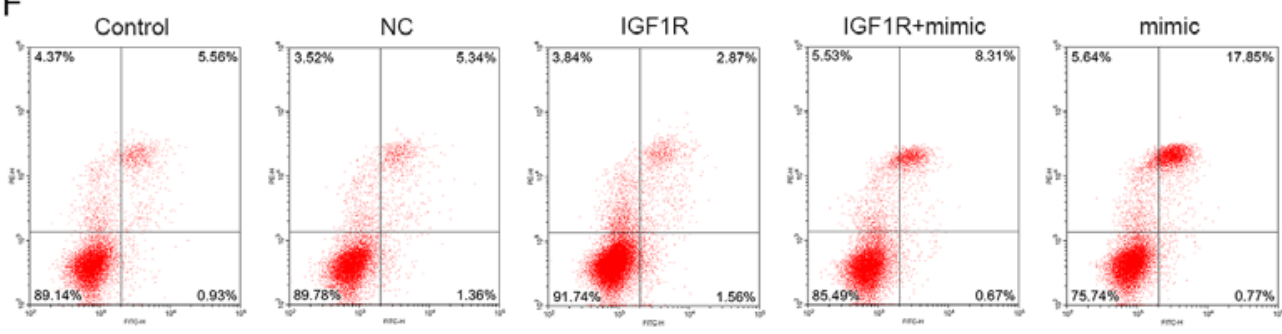

G
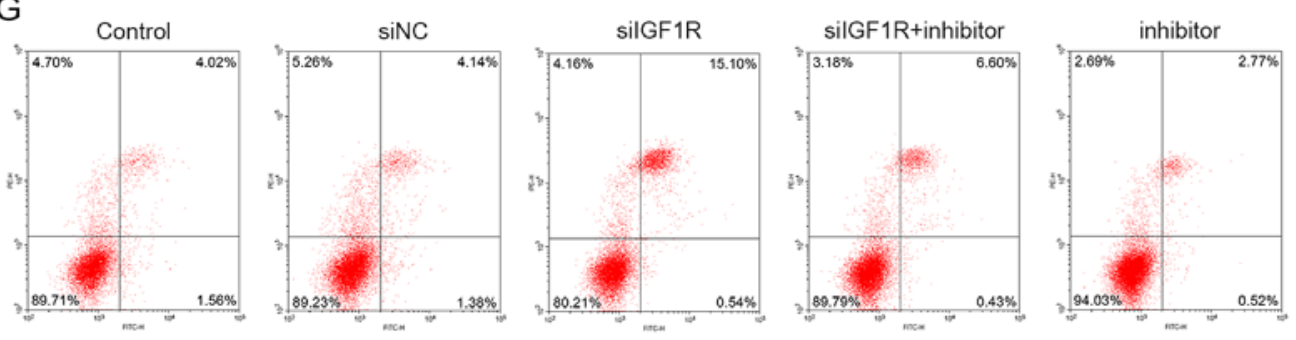

$\mathrm{E}$

MDA-MB-231

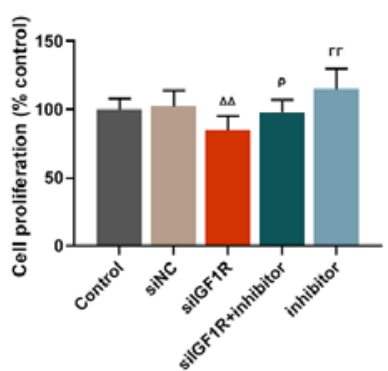

MCF-7

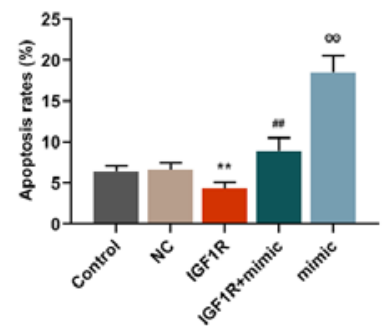

MDA-MB-231

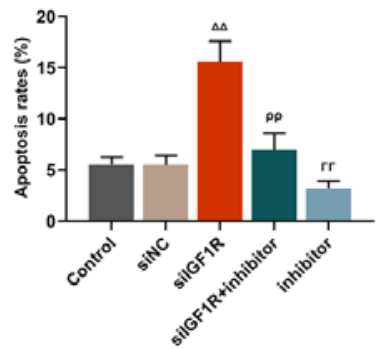

Figure 5. miR-589-3p mimics could partially reverse the effect of IGF1R overexpression on breast cancer cell proliferation and apoptosis. (A) TargetScan predicted the target gene of miR-589-3p. (B and C) Luciferase activity of the miR-589-3p target gene was detected by luciferase assay. (D and E) Cell proliferation of MCF-7 and MDA-MB-231 cells detected by MTT assay. (F and G) Flow cytometry was used to detect MCF-7 and MDA-MB-231 cell apoptosis. All experiments were repeated three times. ${ }^{* *} \mathrm{P}<0.01$ vs. blank or $\mathrm{NC} ;{ }^{\# \#} \mathrm{P}<0.01$ vs. IGF1R; ${ }^{\ominus}{ }^{\Theta} \mathrm{P}<0.01$ vs. IGF1R + miR-589-3p mimic; ${ }^{\Delta \Delta} \mathrm{P}<0.01$ vs. si-NC; ${ }^{\circ} \mathrm{P}<0.05$ and ${ }^{\rho \rho} \mathrm{P}<0.001$ vs. siIGF1R; ${ }^{\Gamma \Gamma} \mathrm{P}<0.01$ vs. siIGF1R + miR-589-3p inhibitor. IGF1R, insulin-like growth factor 1 receptor; mut, mutant; miR, microRNA; NC, negative control; si, small interfering; wt, wild type.

level was observed in any condition. Subsequently, western blotting was performed to analyse the protein expression of IGF1R, p-Akt and Akt. The results were similar to those from RT-qPCR. In particular, miR-589-3p mimic partially reversed IGF1R and p-Akt high protein expression in the IGF1R group $(\mathrm{P}<0.001$; Fig. 7C-E), whereas the Akt protein expression did not significantly change. Subsequently, the ratio p-Akt/Akt was downregulated in siIGF1R group $(\mathrm{P}<0.001)$, whereas the ratio $\mathrm{p}$-Akt/Akt was increased in the siIGF1R + inhibitor and inhibitor groups $(\mathrm{P}<0.001$; Fig. $7 \mathrm{~F}-\mathrm{H})$. These findings suggested that miR-589-3p may downregulate IGF1R and p-Akt expression in breast cancer cells.

\section{Discussion}

The results from the present study demonstrated that TINCR was highly expressed in MCF-7 and MDA-MB-231 breast cancer cells, and that TINCR promoted the proliferation and migratory and invasive abilities of breast cancer cells and inhibited cancer cell apoptosis. These findings were consistent with a previous study (21). Furthermore, to the best of our knowledge, the present study was the first to demonstrate that miR-589-3p may act as a targeted miRNA for TINCR, and that its expression was inhibited by TINCR. In breast cancer cells that were co-transfected with miR-589-3p mimic and pc-TINCR, the promoting effects of TINCR on cancer cell proliferation and migratory and invasive abilities were attenuated by miR-589-3p mimic. In addition, this study demonstrated that the target gene IGF1R of miR-589-3p promoted the proliferation and migratory and invasive abilities of breast cancer cells and inhibited their apoptosis, which may be partially reversed by miR-589-3p mimic. These effects were obtained via inhibition of the IGF1R-Akt pathway. 


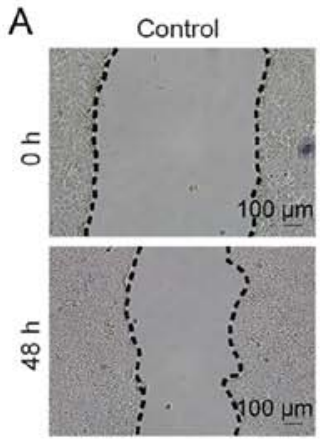

B
NC

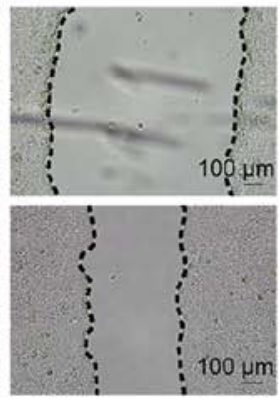

MCF-7

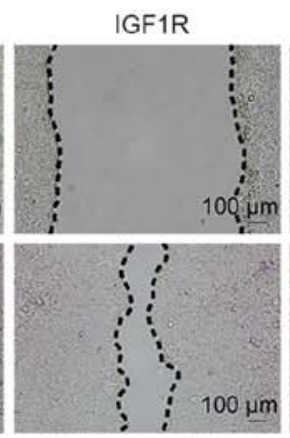

C

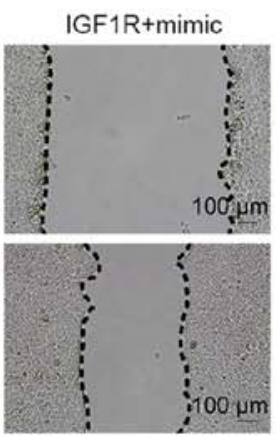

MDA-MB-231

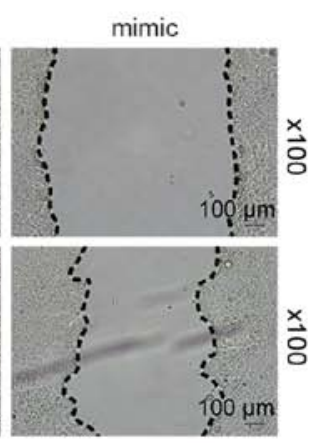

- $\stackrel{x}{8}$
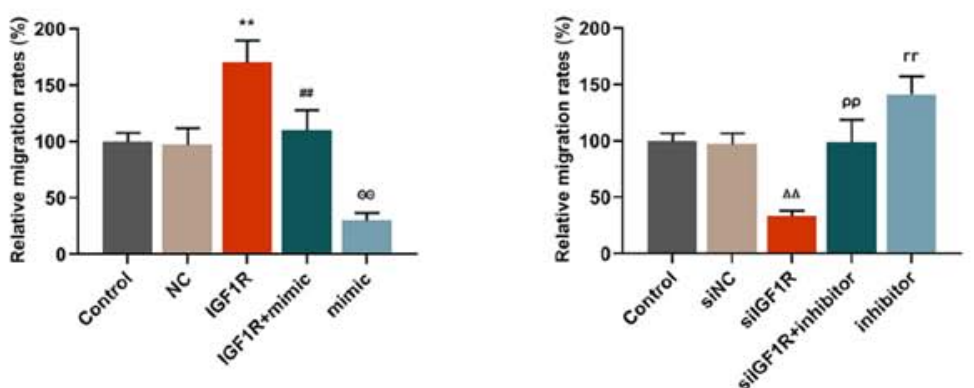

D
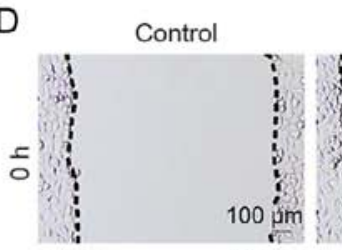

siNC

silGF1R

silGF1R+inhibitor

inhibitor
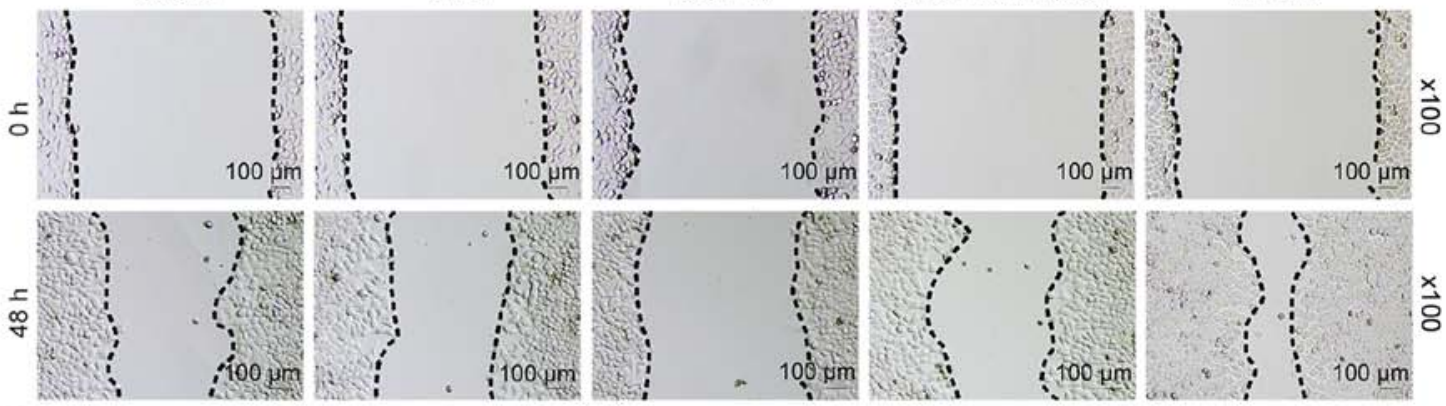

$E$

$\mathrm{NC}$

IGF1R+mimic

mimic

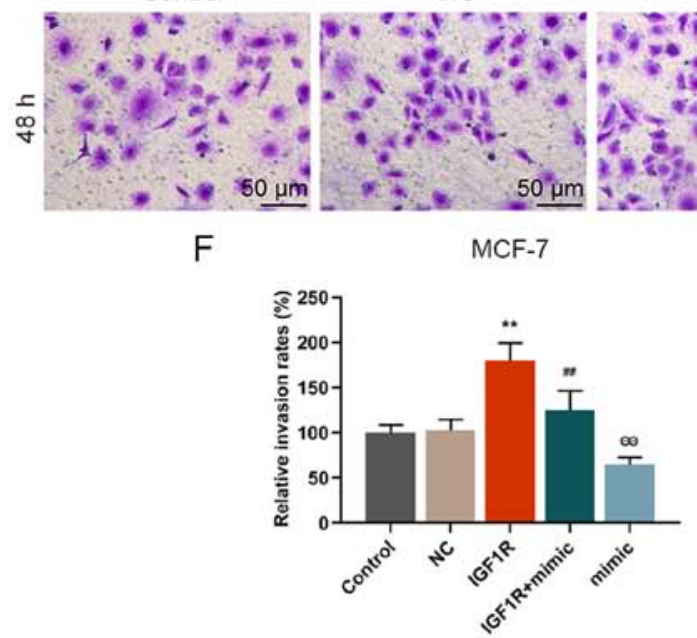

IGF1R
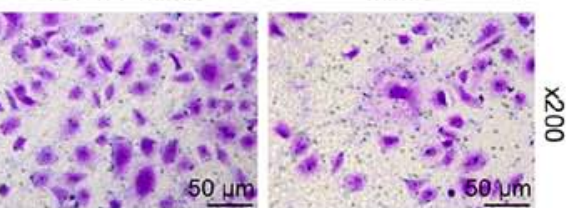

G

MDA-MB-231

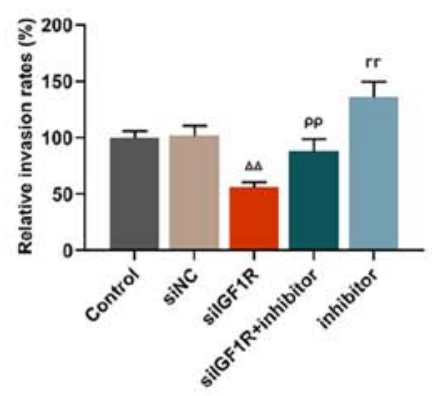

$\mathrm{H}$

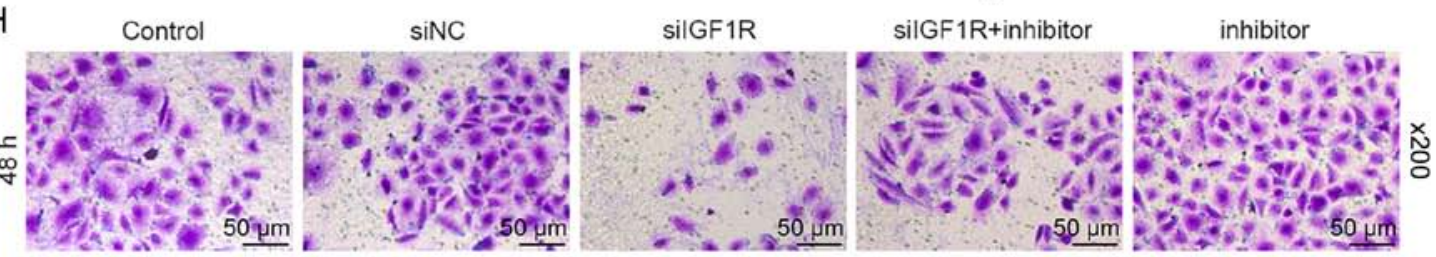

Figure 6. miR-589-3p mimic inhibited the migratory and invasive abilities of breast cancer cells by down-regulating IGF1R expression. (A-D) Wound healing assay was used to detect the migratory ability of MCF-7 and MDA-MB-231 cells. (E-H) Transwell assay was used to detect the invasive ability of MCF-7 and MDA-MB-231 cells. All experiments were repeated three times. ${ }^{* *} \mathrm{P}<0.01 \mathrm{vs}$. NC; ${ }^{\# \#} \mathrm{P}<0.01$ vs. IGF1R; ${ }^{\ominus} \mathrm{P}<0.01$ vs. IGF1R + miR-589-3p mimic; ${ }^{\Delta \Lambda} \mathrm{P}<0.01 \mathrm{vs}$. siNC; ${ }^{\rho \rho} \mathrm{P}<0.01$ vs. si-IGF1R; ${ }^{\Gamma \Gamma} \mathrm{P}<0.01$ vs. si-IGF1R + miR-589-3p inhibitor. IGF1R, insulin-like growth factor 1 receptor; miR, microRNA; NC, negative control; si, small interfering. 
A

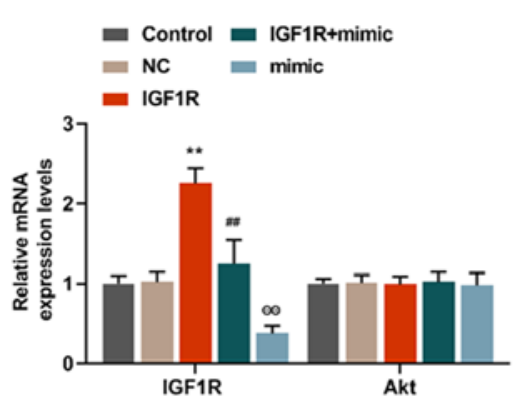

B

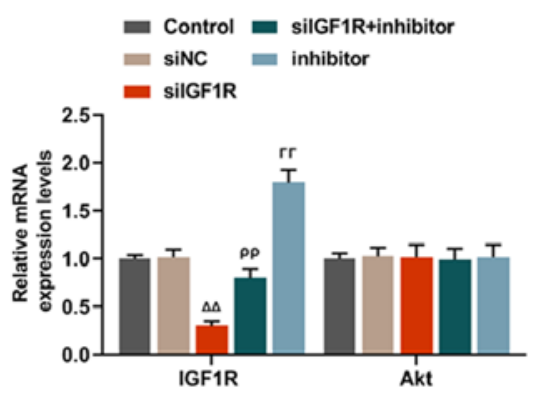

C

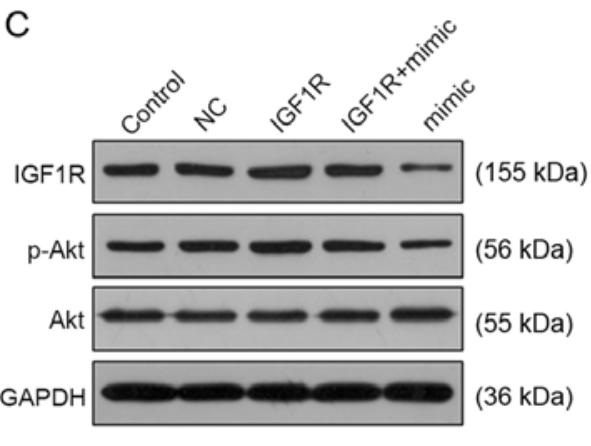

$\mathrm{F}$

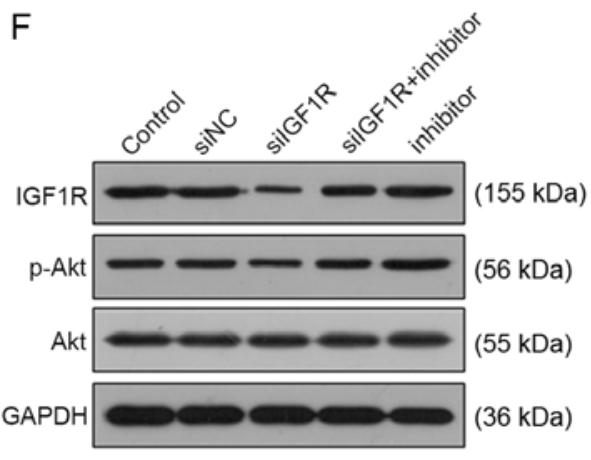

D

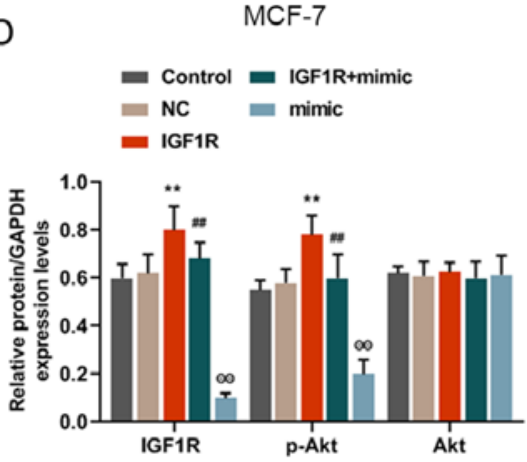

G

E MCF-7

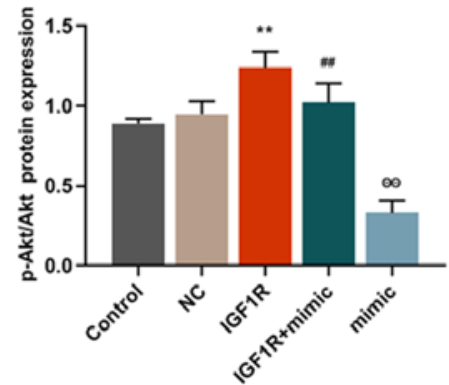

$\mathrm{H}$

MDA-MB-231

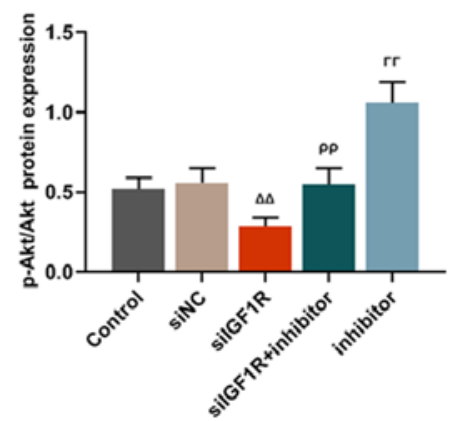

Figure 7. miR-589-3p regulated the activation of Akt pathway by targeting IGF1R in breast cancer cells. (A and B) Reverse transcription-quantitative PCR was used to detect IGF1R and Akt expression levels. (C-E) Western blotting used to detect the protein levels of IGF1R, p-AKT and Akt in MCF-7 cells. (F-H) Western blotting used to detect the protein levels of IGF1R, p-AKT and Akt in MDA-MB-231 cells. All experiments were repeated three times. GAPDH was used as an internal reference. ${ }^{* *} \mathrm{P}<0.01$ vs. NC; ${ }^{\# /} \mathrm{P}<0.01$ vs. IGF1R; ${ }^{\Theta} \mathrm{P}<0.01$ vs. IGF1R + miR-589-3p mimic; ${ }^{\Delta \Delta} \mathrm{P}<0.01$ vs. siNC; ${ }^{\rho} \mathrm{P}<0.01$ vs. siIGF1R; ${ }^{\Gamma \Gamma} \mathrm{P}<0.01$ vs. siIGF1R + miR-589-3p inhibitor. IGF1R, insulin-like growth factor 1 receptor; miR, microRNA; NC, negative control; p, phospho; si, small interfering.

In the last decades, the prognosis of patients with breast cancer has greatly improved thanks to the constant advances in medical technologies and techniques. However, it remains crucial to make progress on the development of novel diagnosis tools and therapeutic options for patients. Tumor presentation varies among molecular subtypes, suggesting that tumors of different subtypes may be useful in selecting local therapy (30). Targeted therapeutic drugs could aim different genes and signalling pathways in breast cancer. For example, agents targetin estrogen receptor (ER) and HER2, such as tamoxifen and trastuzumab, are the most extensively used therapeutics in breast cancer $(31,32)$. These therapeutic drugs have therefore been designed for different molecular subtypes. However, the existence of chemoresistance and the lack of therapeutic drugs for triple-negative breast cancer remain to be resolved $(33,34)$. It is therefore crucial to explore the underlying mechanisms of breast cancer metastasis and recurrence, in order to determine potential novel intervention targets and develop more effective treatment strategies. miRNAs represent a class of endogenous single-stranded non-coding RNAs of 20-24 nt in length, which are able to bind to the 3'UTR regions of mRNA, leading to gene silencing at post-transcriptional levels. miRNAs are widely involved in cell proliferation, organ development, immune response and tumor formation among other processes. Previous studies reported that miRNAs are closely related to the occurrence and development of certain types of tumor (35-37). Not only they can function as tumor promoters but they can also function as oncogenes. miRNAs in the plasma can also 
be used as biomarkers for early diagnosis of certain tumors. It has been reported that exosomal microRNA-21 could be considered as a potential biomarker for the early diagnosis of pancreatic cancer using a tethered cationic lipoplex nanoparticle biochip (38). Furthermore, exosomal microRNA-210 is a potentially non-invasive biomarker for the diagnosis and prognosis of glioma (39). In breast cancer, $>30$ miRNAs have been confirmed to be associated with breast cancer (40). For example, miR-145 can inhibit cancer cell proliferation and invasion via the regulation of N-RAS and vascular endothelial growth factor A in triple-negative breast cancer, miR-145 can inhibit angiogenesis in breast cancer tissues (41). Furthermore, miR-203, which is lowly expressed in metastatic breast cancer tissues, can promote breast cancer cell metastasis via upregulation of snail family transcriptional repressor 2 (42). In addition, it was reported that the proto-oncogene miR-210 is highly expressed in breast cancer tissues, which is associated with poor prognosis of patients with breast cancer (43). The present study demonstrated that miR-589-3p overexpression could partially reverse the effects of TINCR on breast cancer cell proliferation and migratory and invasive abilities and on the inhibition of breast cancer cell apoptosis. Similarly, Cesarini et al (44) reported that miR-589-3p can inhibit the proliferation and migratory and invasive abilities of glioblastoma cells, suggesting its anti-cancer effect.

Insulin-like growth factors (IGFS) represent a class of growth factors that serve crucial roles in the growth and differentiation of bones and muscles $(45,46)$. The main biological activities of IGFS are mediated by IGFR1. IGF1R is a transmembrane tyrosine kinase receptor that plays a vital role in cell mitosis, proliferation, differentiation and apoptosis (47). Loughran et al (48) confirmed that IGF1R overexpression can cause cell division and proliferation, increasing therefore the risk of tumorigenesis; however, cell malignant transformation is suppressed following IGF1R downregulation (49). In 1992 , De Leon et al (50) reported that IGF-I and IGF-II, which are effective mitogens in the breast cancer cells MCF-7, can promote cancer cell proliferation. Turner et al (51) reported that IGF1R expression is increased in resected breast cancer tumor tissues and is associated with early recurrence. Powell et al (52) demonstrated that the commonly inherited IGF1R variant (rs2016347) reduces breast cancer risk by enhancing mammary gland involution. In addition, triptolide and IGF1R inhibitor (AG1024) can synergistically inhibit the proliferation and induce the apoptosis of triple-negative breast cancer cells (53). These studies indicated that IGF1R serve some essential roles in the occurrence and development of breast cancer. IGF1R is widely expressed in various cells of the body, and PI3K-Akt and ERK-MAPK signalling pathways are associated with the occurrence and development of malignant tumors. The signalling pathways regulated by IGF1R include PI3K-Akt and ERK-MAPK pathways (54). Akt is a serine/threonine protein kinase that is the most important target in the PI3K-Akt signalling pathway. The effects of Akt on regulatory mechanisms are dependent on p-Akt that promotes Akt activation, serving therefore a central role in the transmission of information (55). Previous studies confirmed that Akt can regulate the proliferation, migration, invasion and apoptosis of tumor cells via multiple signalling pathways, and also mediate tumor angiogenesis and tumor resistance $(56,57)$. Blocking or inhibiting Akt expression could therefore be effective in cancer treatment. Similarly, the present study demonstrated that miR-589-3p may inhibit breast cancer cell proliferation by decreasing the expression of IGF1R and p-AKT.

Some inhibitors of IGF1R and Akt have been used in the treatment of breast cancer, including NVP-AEW541 (58), OSI-906 (59) and MK-2206 (60). Inhibitors could be used in combination, or multi-target drugs should be developed. de Lint et al (59) reported that the combination of IGF1R inhibitors and PI3K inhibitors has a therapeutic effect on certain patients with triple-negative breast cancer. In the present study, not only miR-589-3p could partially reverse the effect of TINCR on breast cancer cells but it also inhibited the proliferation and migratory and invasive abilities of breast cancer cells by inhibiting the IGF1R-Akt pathway, promoting therefore cancer cell apoptosis, which showed its dual regulatory effect. These findings provided a reliable basis for miRNA application in the treatment of breast cancer, which could improve the prognosis of patients with breast cancer. However, this study presented some limitations, and whether IGF1R or Akt inhibitors could have therapeutic roles in animal models of breast cancer requires further investigation. In addition, the stimulating effects of TINCR on the proliferation and migratory and invasive abilities of breast cancer cells through regulation of the miR-589-3p/IGF1R/Akt axis should be further confirmed by in vivo experiments.

\section{Acknowledgements}

Not applicable.

\section{Funding}

No funding was received.

\section{Availability of data and materials}

The datasets used and/or analyzed during the current study are available from the corresponding author on reasonable request.

\section{Authors' contributions}

FG and XZ provided substantial contributions to the conception and design of the study. QZ and QH acquired, analyzed and interpreted data. FG and XZ drafted and critically revised the manuscript for important intellectual content. All authors agreed to be accountable for all aspects of the work in ensuring that questions related to the accuracy or integrity of the work were appropriately investigated and resolved. All authors read and approved the final manuscript.

\section{Ethics approval and consent to participate}

The present study has been approved by the Ethics Committee of Affiliated Zhongshan Hospital of Dalian University (approval no. 201112013RXW) and all procedures were performed in accordance with the 1964 Declaration of Helsinki and its later amendments or comparable ethical standards. All patients signed informed consent. 


\section{Patient consent for publication}

Not applicable.

\section{Competing interests}

The authors declare that they have no competing interests.

\section{References}

1. Woolston C: Breast cancer. Nature 527: S101, 2015.

2. DeSantis CE, Ma J, Gaudet MM, Newman LA, Miller KD, Goding Sauer A, Jemal A and Siegel RL: Breast cancer statistics, 2019. CA Cancer J Clin 69: 438-451, 2019.

3. Ng CK, Martelotto LG, Gauthier A, Wen HC, Piscuoglio S, Lim RS, Cowell CF, Wilkerson PM, Wai P, Rodrigues DN, et al: Intra-tumor genetic heterogeneity and alternative driver genetic alterations in breast cancers with heterogeneous HER2 gene amplification. Genome Biol 16: 107, 2015.

4. Carmichael H, Matsen C, Freer P, Kohlmann W, Stein M, Buys SS and Colonna S: Breast cancer screening of pregnant and breastfeeding women with BRCA mutations. Breast Cancer Res Treat 162: 225-230, 2017.

5. Nik-Zainal S, Davies H, Staaf J, Ramakrishna M, Glodzik D, Zou X, Martincorena I, Alexandrov LB, Martin S, Wedge DC, et al: Landscape of somatic mutations in 560 breast cancer whole-genome sequences. Nature 534: 47-54, 2016.

6. Bray F, Ferlay J, Soerjomataram I, Siegel RL, Torre LA and Jemal A: Global cancer statistics 2018: GLOBOCAN estimates of incidence and mortality worldwide for 36 cancers in 185 countries. CA Cancer J Clin 68: 394-424, 2018.

7. Siegel RL, Miller KD and Jemal A: Cancer statistics, 2016. CA Cancer J Clin 66: 7-30, 2016.

8. ENCODE Project Consortium: An integrated encyclopedia of DNA elements in the human genome. Nature 489: 57-74, 2012.

9. Renganathan A and Felley-Bosco E: Long noncoding RNAs in cancer and therapeutic potential. Adv Exp Med Biol 1008: 199-222, 2017.

10. Chen Q, Zhu C, Jin Y, Si X, Jiao W, He W, Mao W, Li M and Luo G: Plasma long non-coding RNA RP11-438N5.3 as a novel biomarker for non-small cell lung cancer. Cancer Manag Res 12 . $1513-1521,2020$

11. Shen X, Xue Y, Cong H, Wang X, Fan Z, Cui X and Ju S Circulating lncRNA DANCR as a potential auxillary biomarker for the diagnosis and prognostic prediction of colorectal cancer. Biosci Rep 40: BSR20191481, 2020.

12. Zhang $Y$ and Tang L: The application of lncRNAs in cancer treatment and diagnosis. Recent Pat Anticancer Drug Discov 13: 292-301, 2018

13. Kretz M, Siprashvili Z, Chu C, Webster DE, Zehnder A, Qu K, Lee CS, Flockhart RJ, Groff AF, Chow J, et al: Control of somatic tissue differentiation by the long non-coding RNA TINCR Nature 493: 231-235, 2013.

14. Kretz M: TINCR, staufen1, and cellular differentiation. RNA Biol 10: 1597-1601, 2013

15. Xu TP, Wang YF, Xiong WL, Ma P, Wang WY, Chen WM, Huang MD, Xia R, Wang R, Zhang EB, et al: E2F1 induces TINCR transcriptional activity and accelerates gastric cancer progression via activation of TINCR/STAU1/CDKN2B signaling axis. Cell Death Dis 8: e2837, 2017.

16. Zhang ZY, Lu YX, Zhang ZY, Chang YY, Zheng L, Yuan L, Zhang F, Hu YH,Zhang WJ and Li XN: Loss of TINCR expression promotes proliferation, metastasis through activating EpCAM cleavage in colorectal cancer. Oncotarget 7: 22639-22649, 2016.

17. Chen Z, Liu Y, He A, Li J, Chen M, Zhan Y, Lin J, Zhuang C, Liu L, Zhao G, et al: Theophylline controllable RNAi-based genetic switches regulate expression of lncRNA TINCR and malignant phenotypes in bladder cancer cells. Sci Rep 6: 30798, 2016.

18. Hu M, Han Y, Zhang Y, Zhou Y and Ye L: lncRNA TINCR sponges miR-214-5p to upregulate ROCK1 in hepatocellular carcinoma. BMC Med Genet 21: 2, 2020.

19. Gao YW, Ma F, Xie YC, Ding MG, Luo LH, Jiang S, Rao L and Liu XL: Spl-induced upregulation of the long noncoding RNA TINCR inhibits cell migration and invasion by regulating $\mathrm{miR}-107 / \mathrm{miR}-1286$ in lung adenocarcinoma. Am J Transl Res 11: 4761-4775, 2019
20. Li R, Wang Y, Xu Y, He X and Li Y: Silencing the long noncoding RNA, TINCR, a molecular sponge of miR-335, inhibits the malignant phenotype of epithelial ovarian cancer via FGF2 suppression. Int J Oncol 55: 1110-1124, 2019.

21. Li S, Li J, Li H, Gao M, Li N, Wang Y, Tong L, Song M and Yin Z: Clinicopathological and prognostic significance of TINCR in caner: A meta-analysis. Pathol Res Pract 215: 152596, 2019.

22. Dong H, Hu J, Zou K, Ye M, Chen Y, Wu C, Chen X and Han M: Activation of LncRNA TINCR by H3K27 acetylation promotes Trastuzumab resistance and epithelial-mesenchymal transition by targeting MicroRNA-125b in breast cancer. Mol Cancer 18 : 3, 2019.

23. Liu Y, Du Y, Hu X, Zhao L and Xia W: Up-regulation of ceRNA TINCR by SP1 contributes to tumorigenesis in breast cancer. BMC Cancer 18: 367, 2018

24. Li J, Gao C, Liu C, Zhou C, Ma X, Li H, Li J, Wang X, Qi L, Yao Y, et al: Four lncRNAs associated with breast cancer prognosis identified by coexpression network analysis. J Cell Physiol 234: 14019-14030, 2019.

25. Xu S, Kong D, Chen Q, Ping Y and Pang D: Oncogenic long noncoding RNA landscape in breast cancer. Mol Cancer 16: 129, 2017.

26. Mah SM, Buske C, Humphries RK and Kuchenbauer F: miRNA*: A passenger stranded in RNA-induced silencing complex? Crit Rev Eukaryot Gene Expr 20: 141-148, 2010.

27. Backes C, Meese E and Keller A: Specific miRNA disease biomarkers in blood, serum and plasma: Challenges and prospects. Mol Diagn Ther 20: 509-518, 2016.

28. Chen Z, Liu H, Yang H, Gao Y, Zhang G and Hu J: The long noncoding RNA, TINCR, functions as a competing endogenous RNA to regulate PDK1 expression by sponging miR-375 in gastric cancer. Onco Targets Ther 10: 3353-3362, 2017.

29. Livak KJ and Schmittgen TD: Analysis of relative gene expression data using real-time quantitative PCR and the 2(-Delta Delta C(T)) method. Methods 25: 402-408, 2001

30. Wiechmann L, Sampson M, Stempel M, Jacks LM, Patil SM, King T and Morrow M: Presenting features of breast cancer differ by molecular subtype. Ann Surg Oncol 16: 2705-2710, 2009.

31. Nagini S: Breast cancer: Current molecular therapeutic targets and new players. Anticancer Agents Med Chem 17: 152-163, 2017.

32. Kast K, Schoffer O,Link T, Forberger A, Petzold A, Niedostatek A, Werner C, Klug SJ, Werner A, Gatzweiler A, et al: Trastuzumab and survival of patients with metastatic breast cancer. Arch Gynecol Obstet 296: 303-312, 2017.

33. Saw PE, Park J, Jon S and Farokhzad OC: A drug-delivery strategy for overcoming drug resistance in breast cancer through targeting of oncofetal fibronectin. Nanomedicine 13: 713-722, 2017.

34. DeMichele A, Yee D and Esserman L: Mechanisms of resistance to neoadjuvant chemotherapy in breast cancer. N Engl J Med 377: 2287-2289, 2017.

35. Qadir MI and Faheem A: miRNA: A diagnostic and therapeutic tool for pancreatic cancer. Crit Rev Eukaryot Gene Expr 27: 197-204, 2017.

36. Ganapathy K, Staklinski S, Hasan MF, Ottman R, Andl T, Berglund AE, Park JY and Chakrabarti R: Multifaceted function of MicroRNA-299-3p fosters an antitumor environment through modulation of androgen receptor and VEGFA signaling pathways in prostate cancer. Sci Rep 10: 5167, 2020.

37. Indrieri A, Carrella S, Carotenuto P, Banfi S and Franco B: The pervasive role of the miR-181 Family in development, neurodegeneration, and cancer. Int J Mol Sci 21: E2092, 2020.

38. Pu X, Ding G, Wu M, Zhou S, Jia S and Cao L: Elevated expression of exosomal microRNA-21 as a potential biomarker for the early diagnosis of pancreatic cancer using a tethered cationic lipoplex nanoparticle biochip. Oncol Lett 19: 2062-2070, 2020.

39. Lan F, Yue X and Xia T: Exosomal microRNA-210 is a potentially non-invasive biomarker for the diagnosis and prognosis of glioma. Oncol Lett 19: 1967-1974, 2020.

40. Nassar FJ, Nasr R and Talhouk R: MicroRNAs as biomarkers for early breast cancer diagnosis, prognosis and therapy prediction. Pharmacol Ther 172: 34-49, 2017.

41. Zou C, Xu Q, Mao F, Li D, Bian C, Liu LZ, Jiang Y, Chen X, Qi Y, Zhang X, et al: MiR-145 inhibits tumor angiogenesis and growth by N-RAS and VEGF. Cell Cycle 11: 2137-2145, 2012.

42. Zhang Z, Zhang B, Li W, Fu L, Fu L, Zhu Z and Dong JT: Epigenetic silencing of miR-203 upregulates SNAI2 and contributes to the invasiveness of malignant breast cancer cells. Genes Cancer 2: 782-791, 2011 
43. Tang Y, Zhou X, Ji J, Chen L, Cao J, Luo J and Zhang S: High expression levels of miR-21 and miR-210 predict unfavorable survival in breast cancer: A systemic review and meta-analysis. Int J Biol Markers 30: e347-e358, 2015.

44. Cesarini V, Silvestris DA, Tassinari V, Tomaselli S, Alon S, Eisenberg E, Locatelli $\mathrm{F}$ and Gallo A: ADAR2/miR-589-3p axis controls glioblastoma cell migration/invasion. Nucleic Acids Res 46: 2045-2059, 2018.

45. Duan C, Ren H and Gao S: Insulin-like growth factors (IGFs), IGF receptors, and IGF-binding proteins: Roles in skeletal muscle growth and differentiation. Gen Comp Endocrinol 167: 344-351, 2010.

46. Patil AS, Sable RB and Kothari RM: Role of insulin-like growth factors (IGFs), their receptors and genetic regulation in the chondrogenesis and growth of the mandibular condylar cartilage. J Cell Physiol 227: 1796-1804, 2012.

47. Simpson A, Petnga W, Macaulay VM, Weyer-Czernilofsky U and Bogenrieder T: Insulin-like growth factor (IGF) pathway targeting in cancer: Role of the IGF Axis and opportunities for future combination studies. Target Oncol 12: 571-597, 2017.

48. Loughran G, Huigsloot M, Kiely PA, Smith LM, Floyd S, Ayllon V and O'Connor R: Gene expression profiles in cells transformed by overexpression of the IGF-I receptor. Oncogene 24: 6185-6193, 2005.

49. Werner H and Sarfstein R: Transcriptional and epigenetic control of IGF1R gene expression: Implications in metabolism and cancer. Growth Horm IGF Res 24: 112-118, 2014.

50. De Leon DD, Wilson DM, Powers M and Rosenfeld RG: Effects of insulin-like growth factors (IGFs) and IGF receptor antibodies on the proliferation of human breast cancer cells. Growth Factors 6: 327-336, 1992.

51. Turner BC, Haffty BG, Narayanan L, Yuan J, Havre PA, Gumbs AA, Kaplan L, Burgaud JL, Carter D, Baserga R and Glazer PM: Insulin-like growth factor-I receptor overexpression mediates cellular radioresistance and local breast cancer recurrence after lumpectomy and radiation. Cancer Res 57: 3079-3083, 1997.

52. Powell MJ, Dufault SM, Henry JE, Allison AC, Cora R and Benz CC: Pregnancy hypertension and a commonly inherited IGF1R variant (rs2016347) reduce breast cancer risk by enhancing mammary gland involution. J Oncol 2019: 6018432, 2019.
53. Wu H, Sun T and Bi R: Inhibition of insulin-like growth factor 1 signaling synergistically enhances the tumor suppressive role of triptolide in triple-negative breast cancer cells. Oncol Lett 18: 822-829, 2019.

54. Riedemann J and Macaulay VM: IGF1R signalling and its inhibition. Endocr Relat Cancer 13 (Suppl 1): S33-S43, 2006.

55. Jonassen AK, Sack MN, Mjos OD and Yellon DM: Myocardial protection by insulin at reperfusion requires early administration and is mediated via Akt and p70s6 kinase cell-survival signaling. Circ Res 89: 1191-1198, 2001.

56. Nitulescu GM, Van De Venter M, Nitulescu G, Ungurianu A, Juzenas P, Peng Q, Olaru OT, Grădinaru D, Tsatsakis A, Tsoukalas $\mathrm{D}$, et al: The Akt pathway in oncology therapy and beyond (Review). Int J Oncol 53: 2319-2331, 2018.

57. Mundi PS, Sachdev J, McCourt C and Kalinsky K: AKT in cancer: New molecular insights and advances in drug development. Br J Clin Pharmacol 82: 943-956, 2016.

58. Hartog H, Van Der Graaf WT, Boezen HM and Wesseling J: Treatment of breast cancer cells by IGF1R tyrosine kinase inhibitor combined with conventional systemic drugs. Anticancer Res 32: 1309-1318, 2012.

59. de Lint K, Poell JB, Soueidan H, Jastrzebski K, Vidal Rodriguez J, Lieftink C, Wessels LF and Beijersbergen RL: Sensitizing triple-negative breast cancer to PI3K inhibition by cotargeting IGF1R. Mol Cancer Ther 15: 1545-1556, 2016.

60. Chen X, Cui D, Bi Y, Shu J, Xiong X and Zhao Y: AKT inhibitor MK-2206 sensitizes breast cancer cells to MLN4924, a first-in-class NEDD8-activating enzyme (NAE) inhibitor. Cell Cycle 17: 2069-2079, 2018.

This work is licensed under a Creative Commons Attribution-NonCommercial-NoDerivatives 4.0 International (CC BY-NC-ND 4.0) License. 